\title{
Quantitative Determination and Characterization of a Kashmir Saffron (Crocus sativus L.)-Based Botanical Supplement Using Single- Laboratory Validation Study by HPLC-PDA with LC-MS/MS and HPTLC Investigations
}

\author{
Aboli Girme,* Ganesh Saste, Sandeep Pawar, Chetana Ghule, Amit Mirgal, Saurabh Patel, \\ Anshuly Tiwari, Sautik Ghoshal, Sandip B. Bharate, Sonali S. Bharate, D. Srinivasa Reddy, \\ Ram A. Vishwakarma, and Lal Hingorani
}

Cite This: ACS Omega 2021, 6, 23460-23474

Read Online

ABSTRACT: Food ingredients hold a higher nutritional value as a botanical supplement playing a vital role in modifying and maintaining the physiological conditions that improve human health benefits. The Kashmir saffron (Crocus sativus L; KCS) obtained from dried stigmas is known for its aroma precursors and apocarotenoid derivatives, imparting a wide range of medicinal values and therapeutic benefits. In the present study, a simultaneous determination of apocarotenoids and flavonoids in stigma-based botanical supplements was carried out using analytical investigations. The high-performance thin-layer chroma-

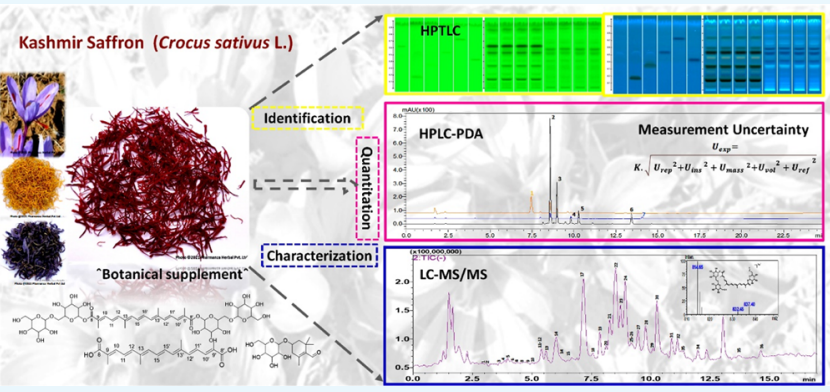
tography-based qualitative analysis of the raw material (stigmas, stamens, and tepals) and stigma extract has been carried out to identify apocarotenoids and flavonoids. The rapid HPLC-PDA method for the simultaneous quantification of KCS apocarotenoids was robust, precise $(<5.0 \%)$, linear $\left(R^{2}>0.99\right)$, and accurate $(80-110 \%)$ as per the single-laboratory validation data. Furthermore, the combined-expanded uncertainty $(95 \%$; $K=2)$ was calculated and found as $0.0035-0.007 \%(<5.0 \%)$ as per the EURACHEM guide for this HPLC analysis. Additionally, an untargeted identification of 36 compounds in the botanical supplement was based on the elution order, UV-vis spectra, mass fragmentation pattern, and standards by ESI-MS/MS analysis with comprehensive chromatographic fingerprinting. Thus, these analytical approaches enable a composite profile of the stigma-based extract as a potential supplement for human health benefits.

\section{INTRODUCTION}

Crocus sativus L., known as saffron, is cultivated as a food crop known for its labor-intensive harvesting of the stigmas from flowers. It is a well-admired and essential food condiment used across the globe. Saffron is prominently cultivated in India (Kashmir saffron, KCS), Spain (Spanish saffron), Iran (Persian saffron), Afghanistan, France, Morocco, and Greece, with suppliers offering them in various grades depending upon their quality. Kashmir Saffron (KCS) is known for its high aroma, deep color, and long and thick threads (stigmas). The primary distribution is in Pulwama (74.60\%), Anantnag, Badgam (16.13\%), Srinagar (6.68\%), and Baramulla districts. This $\mathrm{KCS}$, known as kesar in India, has recently been validated as geographical indications (GI) based on its rich cultivation history and usage from this specific region with agriculture initiatives such as the National Saffron Mission (India). ${ }^{1-6}$ This saffron is available in different grades in local markets as Mongra (detached stigmas from styles), Lacha (attached stigmas with styles), and Zarda (detached styles from stigmas). This regional grading system is independent of Persian,
Spanish, Greek saffron grading. ${ }^{6,7}$ While exploring the phytochemicals, apocarotenoids (picrocrocin, crocetins and crocetin esters, and safranal), terpenoids, and flavonoids (glycoconjugates of Kaempferol) were most evident. ${ }^{8}$

This food condiment is well known for imparting color, flavor, and aroma worldwide. ${ }^{9-17}$ This KCS is also popular folklore and Indian traditional medicine for eye health, skin conditions, digestive ailments, women's health, and other ailments. ${ }^{18,19}$ Recently, this botanical supplement has shown prominent action against neurodegenerative disorders, namely, Alzheimer's ( $\mathrm{AD})$, Parkinson's disease, dementia, and anxiety, due to the presence of bioactive constituents. ${ }^{20-25}$

Received: July 2, 2021

Accepted: August 13, 2021

Published: August 30, 2021 


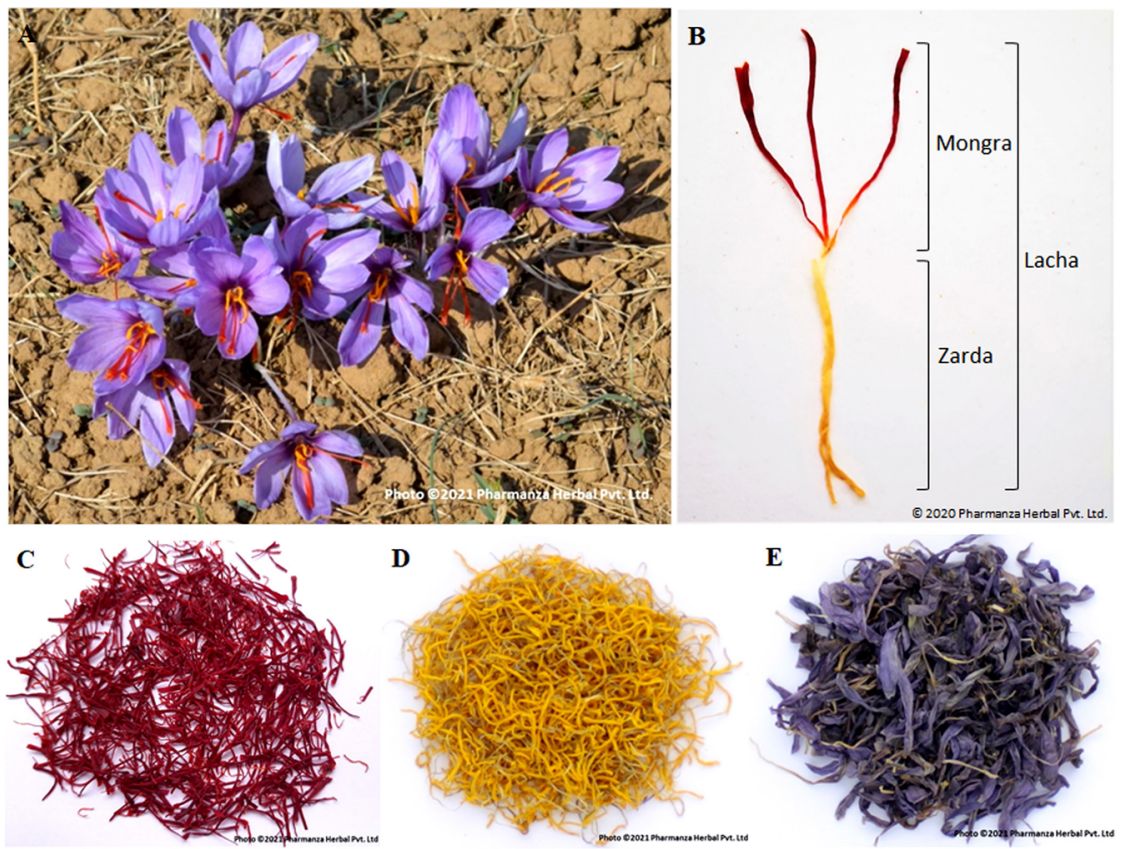

Figure 1. Kashmir saffron (C. sativus L.). Habit (A), local gradings of Kashmir saffron (B), dried stigmas (C), stamens (D), and tepals (E).

Table 1. Identification of Analytes with $R_{f}$ Values by HPTLC Profiling under Optimized Conditions

\begin{tabular}{cllll} 
compound. no. & \multicolumn{1}{c}{ analytes } & $R_{f}$ & before derivatization-UV $(254 \mathrm{~nm})$ & after derivatization-visible \\
$\mathbf{1}$ & picrocrocin & 0.63 & black & yellow \\
$\mathbf{2}$ & trans-4-GG-crocin & 0.15 & light gray & light gray \\
$\mathbf{3}$ & trans-3-Gg-crocin & 0.33 & light gray & light gray \\
$\mathbf{8}$ & kaempferol 3-O- $\beta$-sophoroside & 0.53 & light gray & light yellow \\
$\mathbf{9}$ & kaempferol-O-glucoside & 0.73 & light gray & pale yellow \\
$\mathbf{1 0}$ & quercetin-3,4'-di-O-glucoside & 0.42 & light gray & yellowish-brown \\
\end{tabular}

In our previous research, KCS-based botanical supplement (C. sativus extract, CSE), was evaluated for its neuroprotective potential in vitro and in vivo. Crocins and crocetin were essential in delaying and/or preventing $\mathrm{AD} .^{20,26,27}$ Among secondary metabolites of saffron, crocins are the significant components contributing to its pharmacological properties. Although crocins occur naturally in abundance, however, it undergoes bioactivation in the biological system to produce lipophilic crocetin (aglycone) that crosses the blood-brain barrier. We have previously shown that crocin, trans-crocetin, and safranal display an anti-Alzheimer effect by either $\mathrm{A} \beta$ clearance or blocking neuroinflammation. ${ }^{20,26,28}$ Furthermore, the recent pharmacokinetic study revealed the presence of these crocins and crocetin, with picrocrocin and safranal in vivo after oral administration of CSE, demonstrating its role as a promising botanical lead. ${ }^{29}$ Thus, in the present study, we have carried out quantification studies for these crocins and crocetin. The currently available methods for saffron analysis are based only on one or two marker compounds. Most of the reports lack data on single-laboratory validation or uncertainty of the robust evaluation of these analytical methods. ${ }^{30-32}$ However, the method reported herein comprises seven markers, including four crocetin-esters (crocins), transcrocetin, picrocrocin, and safranal for quantifying the different batches of the KCS.

Herein, a stigma-based extract-standardized botanical supplement (CSE) was characterized by high-performance thin-layer chromatography (HPTLC), reversed-phase high- performance liquid chromatography with a photodiode-array detector (HPLC-PDA), and triple quadrupole mass spectrometry (TQ-MS/MS) analyses. A new HPTLC method was developed as a visual aid for the rapid qualitative analysis of stigmas, stamens, and tepals of KCS along with CSE at 254 and $366 \mathrm{~nm}$. A sensitive HPLC-PDA method was developed to determine the apocarotenoids (picrocrocin, safranal, trans-4GG-crocin, trans-3-Gg-crocin, cis-4-GG-crocin, and trans-2-ggcrocin with trans-crocetin) simultaneously in CSE with singlelaboratory validation and measurement of uncertainty data. In addition, a total of 36 compounds from apocarotenoids and flavonoid classes were identified via HPLC, followed by a comprehensive profile by the MS/MS method. Therefore, the identification by HPTLC fingerprinting, robust quantification by HPLC-PDA, and characterization of MS/MS give the composition of KCS and CSE with its adaptability for any product manufacturers and researchers.

\section{RESULTS AND DISCUSSION}

2.1. Morphological and HPTLC Profiling of KCS Flower. Saffron is a perennial herb, about $20-30 \mathrm{~cm}$ tall, with three types of roots: adventitious, absorbing, and contractile. The number of fragrant flowers arising from each corm is $1-4$, depending upon the size of the corm. Perianth segments are $3-5 \mathrm{~cm}$ in length and $1-2 \mathrm{~cm}$ wide, dark lilac or violet to purple, rarely reticulate veined at the collar, and obovate or oblanceolate with a blunt tip. The anthers are 15$20 \mathrm{~mm}$ long, and the ovary is inferior, three-locular, syncarpous 

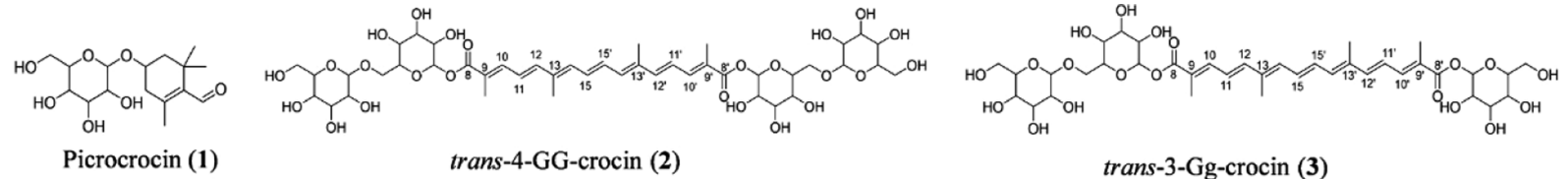

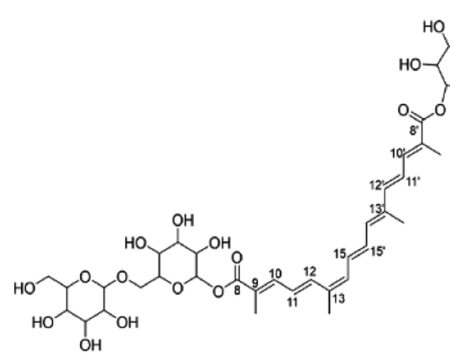

cis-4-GG-crocin (4)

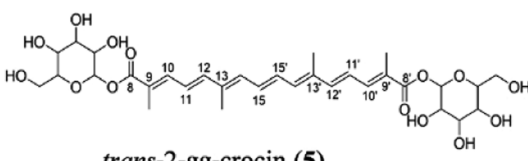
trans-2-gg-crocin (5)

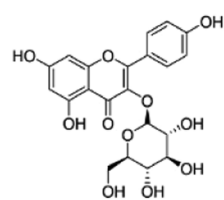

Kaempferol O-glucoside (9)

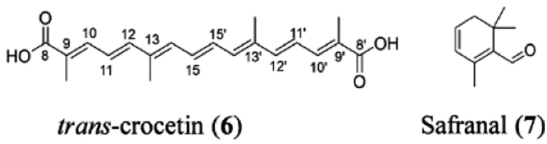
Safranal (7)

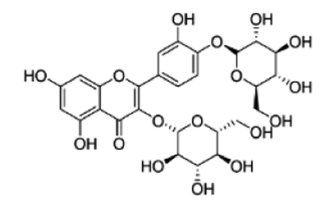

Quercetin-3,4'-di-O-glucoside (10)

Figure 2. Structure of apocarotenoids and flavonoids from Kashmir saffron (C. sativus L.). Picrocrocin (1), trans-4-GG-crocin (2), trans-3-Ggcrocin (3), cis-4-GG-crocin (4), trans-2-gg-crocin (5), trans-crocetin (6), safranal (7), kaempferol-3-O- $\beta$-sophoroside (8), quercetin-3-Osophoroside (9), and quercetin-3,4'-di-O-glucoside (10).

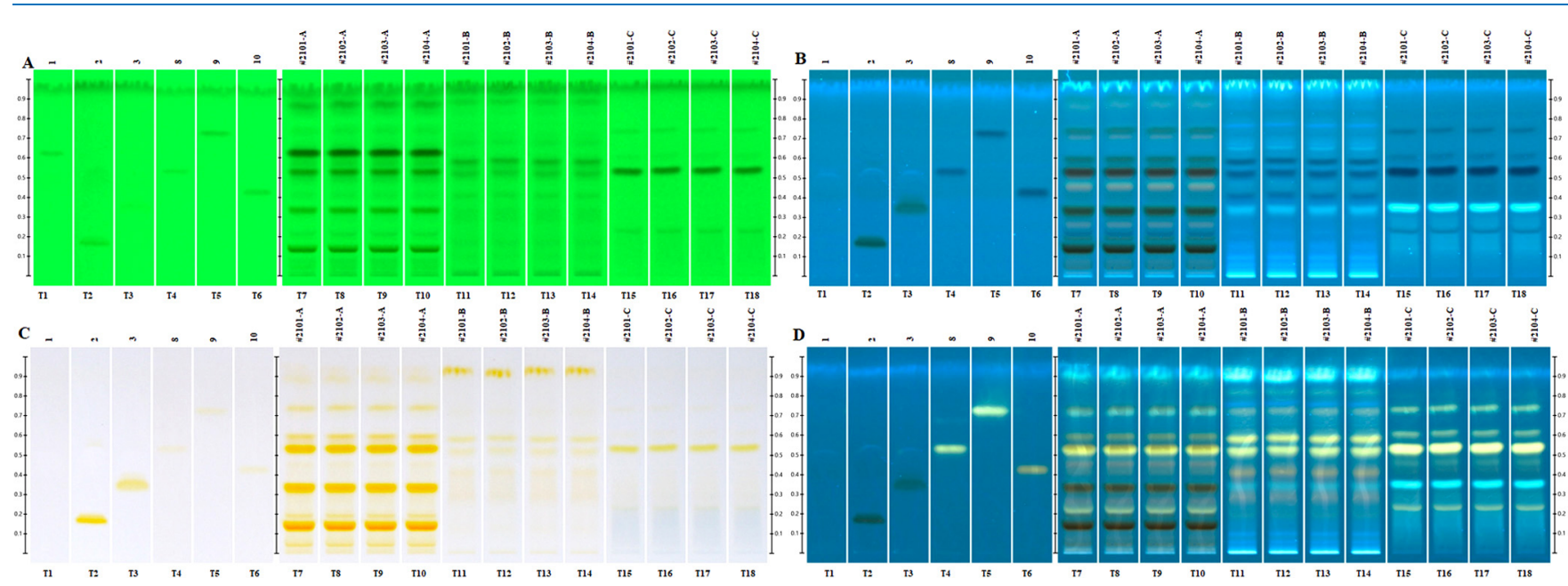

Figure 3. HPTLC fingerprinting of flower parts of Kashmir saffron (KCS) under UV $254 \mathrm{~nm}$ (A), under $366 \mathrm{~nm}$ (B), under white light after derivatization (C), and under UV $366 \mathrm{~nm}$ after derivatization (D); track details: T1-T6: reference standards, where, picrocrocin (1), trans-4-GGcrocin (2), trans-3-Gg-crocin (3), kaempferol-3-O- $\beta$-sophoroside (8), kaempferol-O-glucoside (9), and quercetin-3,4' di- $O$-glucoside (10); T7T10: the stigma of KCS; T11-T14: stamens of KCS; and T15-T18: tepals of KCS.

with an orange-red style situated adjacent to or below the soil surface. A single three-parted pistil with an inferior ovary and a long style terminating with three red stigmas underneath yellow stamens to purple tepals is a characteristic feature of the saffron flower (Figure 1).

Thus, this KCS flower and its parts such as stigmas, stamens, and tepals were further characterized by HPTLC profiling in this study. The mobile phase was developed as ethyl acetate: methanol: water $(9: 2: 1.5 v / v / v)$ on a normal-phase silica gel plate followed by visualization at 254 and $366 \mathrm{~nm}$ and a visiblelight NP-PEG derivatizing reagent. The characteristic $R_{f}$ values at $0.63,0.15,0.33,0.53,0.73$, and 0.42 confirmed the presence of apocarotenoids (1-3) and flavonoids (8-10) under optimized conditions (Table 1) (Figure 2).

The stigma samples showed compounds (1-3 and 8) distinctly at 254 and $366 \mathrm{~nm}$ after derivatization. The compound (3) picrocrocin was present only in stigmas, differentiating it from stamen and tepal samples. It showed a light gray band before derivatization at $254 \mathrm{~nm}$. The compounds (2-3) also displayed a blackish band at $254 \mathrm{~nm}$ before derivatization and at $366 \mathrm{~nm}$ wavelength after derivatization. The flavonoids $(\mathbf{8}-\mathbf{1 0})$ showed characteristic light gray and yellowish-white bands as short-wave UV $254 \mathrm{~nm}$ and long-wave UV $366 \mathrm{~nm}$ before and after derivatization. The tepals showed the presence of yellowish-white bands for compounds (8) and (9). In contrast, the stamens showed a yellowish-orange band of compound (10) at $366 \mathrm{~nm}$ after derivatization and yellowish-brown at visible light (Figure 3).

Along with the above-mentioned KCS compounds, the optimized method shows the following distinctive unknown zones differentiating in the profile of flower parts: before derivatization in stigmas $\left(254 / 366 \mathrm{~nm} ; R_{f} 0.25,0.45\right.$, and 0.74 ), stamens (366 nm; $R_{f} 0.40$ and 0.56 ), and tepals (366 $\left.\mathrm{nm} ; R_{f} 0.35\right)$ and after derivatization in stigmas $\left(R_{f} 0.20,0.45\right)$ and tepals $\left(R_{f} 0.35\right)$ at $366 \mathrm{~nm}$ in KCS samples.

Thus, the above-mentioned method was found suitable for rapid authentication and visual comparison of various flower parts (stigmas, stamens, and tepals). Furthermore, these data provided a novel and cost-effective qualitative analysis for the authentication of the KCS flower. 
Table 2. Linear Regression Range, LOD and LOQ Recovery, and Precision of the Developed HPLC-PDA Method at Different Concentrations of Picrocrocin, trans-4-GG-Crocin, trans-3-Gg-Crocin, cis-4-GG-Crocin, trans-2-gg-Crocin, trans-Crocetin, and Safranal in HPLC-PDA Single-Laboratory-Based Validation

\begin{tabular}{|c|c|c|c|c|c|c|c|c|c|}
\hline analyte & $\mathrm{Rt}$ & $\begin{array}{l}\text { wavelength } \\
\quad(\mathrm{mm})\end{array}$ & $\begin{array}{c}\text { range } \\
(\mu \mathrm{g} / \mathrm{mL})\end{array}$ & $\begin{array}{l}\text { linear regression } \\
\text { equation }^{a}\end{array}$ & $R^{2}$ & $\begin{array}{c}\text { LOD } \\
(\mu \mathrm{g} / \mathrm{mL})\end{array}$ & $\begin{array}{c}\mathrm{LOQ} \\
(\mu \mathrm{g} / \mathrm{mL})\end{array}$ & $\begin{array}{l}\text { average } \\
\text { recovery } \\
( \pm S D)\end{array}$ & $\begin{array}{c}\text { intermediate } \\
\text { precision }(\%, \mathrm{RSD})\end{array}$ \\
\hline picrocrocin & 7.435 & 250 & $0.78-100$ & $y=15392 x-955.9$ & 1.000 & 0.178 & 0.844 & $90.36 \pm 0.55$ & 0.684 \\
\hline trans-4-GG-crocin & 8.555 & 440 & $0.78-100$ & $y=58363 x+20042$ & 0.999 & 0.277 & 0.839 & $82.49 \pm 2.48$ & 0.506 \\
\hline trans-3-Gg-crocin & 8.971 & 440 & $0.31-40$ & $y=82239 x-658.89$ & 0.999 & 0.095 & 0.288 & $86.55 \pm 2.15$ & 1.674 \\
\hline cis-4-GG-crocin & 9.783 & 440 & $3.12-400$ & $y=925.81 x+2302$ & 0.999 & 0.978 & 2.964 & $88.65 \pm 1.95$ & 0.544 \\
\hline trans-2-gg-crocin & 10.261 & 440 & $3.12-400$ & $y=1799.9 x-295.52$ & 0.999 & 0.877 & 2.659 & $90.78 \pm 2.15$ & 0.525 \\
\hline trans-crocetin & 13.419 & 440 & $0.16-20$ & $y=73529 x-2315.7$ & 1.000 & 0.048 & 0.146 & $90.96 \pm 2.63$ & 0.577 \\
\hline safranal & 14.059 & 320 & $0.16-20$ & $y=33447 x+271.5$ & 1.000 & 0.040 & 0.122 & $92.96 \pm 0.91$ & 0.557 \\
\hline
\end{tabular}

2.2. Liquid Chromatography-Photo Diode Array (HPLC-PDA) Analysis. 2.2.1. Matrix Extraction Optimization. Solvents play a critical role in the selective extraction and stability of the compounds, especially carotenoid-based constituents from the plant matrix. Bioactive components of saffron are well known for rapid degradation and isomeric conversion during analysis. Therefore, the matrix extraction was a crucial step to avoid variations in the analysis of saffron and its products. Different solvents and their combination were applied to the samples (CSE) for maximum and consistent separation with the extraction of targeted analytes (1-7) (Figure 2). The extraction solvents were chosen based on the literature and the solubility of targeted apocarotenoids. ${ }^{25,28-32}$ The solvent system 1 [dimethyl sulfoxide (DMSO)/methanol, 20:80 v/v], solvent system 2 (water/methanol, 50:50 v/v), solvent system 3 (water), solvent system 4 (methanol), and solvent system 5 (DMSO) were optimized with ultrasonication-assisted extraction with temperature $\left(25-30{ }^{\circ} \mathrm{C}\right)$ followed by HPLC analysis. A simple liquid-liquid extraction technique of solvent system 1 (DMSO: methanol, 20:80 v/v) was finalized for further analysis based on stability, the maximum response of targeted analytes with reproducible results compared to other solvents (Figures S1-S3, Supporting Information).

2.2.2. Chromatographic Condition Optimization. The HPLC method was developed to achieve a reproducible method by optimizing mobile-phase composition, column oven temperature, wavelength, flow rate, and change columns. A gradient program was used to separate the active constituents in a single run. The detection wavelengths were set according to the ultraviolet (UV) absorption maxima $(\lambda \max )$ of compounds. Apocarotenoids (1 and 7) were detected at 250 and $320 \mathrm{~nm}$, respectively, and (2-6) were found at higher UV absorption $(440 \mathrm{~nm})$. These seven compounds were eluted separately in the following order: 1-7 at Rt 7.435, 8.555, 8.971, 9.783, 10.261, 13.419, and 14.059 min, respectively (Figure S4, Supporting Information).

2.2.3. Single-Laboratory-Based Validation Data. 2.2.3.1. System Suitability. In the suitability of the system, the following parameters were considered to define the optimal performance of the method. (i) Injection of mix standard preparation in duplicate; (ii) peak resolution between $\mathbf{2}$ and 3 which was found to be $>2.0$; (iii) the tailing factor for each analyte, found as $<1.5$; and (iv) the relative retention time for crocins compared to compound (2) which was found to be 1.047 for (3), 1.145 for (4), 1.198 for (5), and 1.567 for (6).
The repeatability precision of area and Rt was $<2.0$ with theoretical plates $(>2000)$.

2.2.3.2. Linearity, $L O D$, and $L O Q$. The mean peak areas of the linearity standards were plotted against concentration. After performing linear regression, the linearity was assessed by determining goodness-of-fit (coefficient of the correlation) at eight different levels to address the wide range of the applicability. The residuals (SSR) over these concentration ranges were determined with AUC (peak area/concentration) at each concentration level (Figure S5, Supporting Information). The linear regression plots in CCS were linear with $R^{2}>$ 0.999 with a reduced $Y$-intercept in most cases for all compounds (Table 2). The range for each analyte was found to be linear and as follows: $0.78-100 \mu \mathrm{g} / \mathrm{mL}(1-2), 0.31-40$ $\mu \mathrm{g} / \mathrm{mL}$ (3), 3.12-400 $\mu \mathrm{g} / \mathrm{mL}(4-5)$, and $0.16-20 \mu \mathrm{g} / \mathrm{mL}$ (6-7). The limits of detection (LODs) for compounds (1-7) were found to be $0.178,0.277,0.095,0.978,0.877,0.048$, and $0.040 \mu \mathrm{g} / \mathrm{mL}$, with limits of quantitation (LOQs) as 0.844 , $0.839,0.288,2.964,2.659,0.146$, and $0.122 \mu \mathrm{g} / \mathrm{mL}$, respectively (Table 3 ).

2.2.3.3. Specificity and Selectivity. The peaks were well separated, with similar retention times to the individual standard injection. Few other peaks were also observed in the samples compared to individual standards. However, the major composition of CSE consists of apocarotenoids ( 1 and 7) detected at 250 and $320 \mathrm{~nm}$, respectively, with compounds 2-6 detected at $440 \mathrm{~nm}$. The relative $\mathrm{Rt}$ of apocarotenoids (2-6) was observed to be similar to those in the mixed standard. The UV spectra of the corresponding standard and the peak purities based on PDA spectral analysis were $>0.99$ in each analyte. The RRt of 2-6 was found at 1.047 for (3), 1.145 for (4), 1.198 for (5), and 1.567 for (6) with 1.00 for (2). Identification of analytes in CSE was determined by comparing peak retention times and the UV spectrum to reference standards. All seven compounds were eluted separately in the following order: compound (1) at $250 \mathrm{~nm}$, compounds (2-6) at $440 \mathrm{~nm}$, and compound (7) at $320 \mathrm{~nm}$.

2.2.3.4. Precision Studies. The intermediate precision of validation was carried out based on the measurement of each analyte content on a different day, and different analysts with concentration levels were $200 \mu \mathrm{g} / \mathrm{mL}(n=6)$ (\% relative standard deviation (RSD), <2.0) (Table 2). The repeatability precision of standards was determined based on measuring the peak area and retention times. Percentage RSD from five replicate injections of standard solution at each concentration was found to be $<2.0$. The repeatability was carried out to determine the content of each analyte in CSE. The sample 
Table 3. Linearity Results and Precision of Area and Retention Time of Standard Solution by HPLC-PDA Methodology ${ }^{a}$

\begin{tabular}{|c|c|c|c|c|c|c|}
\hline \multirow[b]{2}{*}{ compound } & \multirow[b]{2}{*}{ *concentration } & \multicolumn{2}{|c|}{ peak response (AUC) } & \multirow[b]{2}{*}{$R^{2}$} & \multicolumn{2}{|c|}{ retention time $(\mathrm{Rt})$} \\
\hline & & mean peak area & $* * \mathrm{RSD}$ & & mean $(\min )$ & $* * \mathrm{RSD}$ \\
\hline \multirow[t]{8}{*}{ picrocrocin } & 0.78 & 13,119 & 1.244 & \multirow[t]{8}{*}{1.0000} & 7.44 & 0.066 \\
\hline & 1.56 & 25,334 & 0.221 & & 7.45 & 0.132 \\
\hline & 3.13 & 48,211 & 0.648 & & 7.45 & 0.081 \\
\hline & 6.25 & 94,756 & 0.931 & & 7.47 & 0.073 \\
\hline & 12.5 & 186,033 & 0.525 & & 7.46 & 0.060 \\
\hline & 25 & 387,530 & 1.026 & & 7.47 & 0.154 \\
\hline & 50 & 762,967 & 0.242 & & 7.47 & 0.060 \\
\hline & 100 & $1,540,760$ & 0.142 & & 7.46 & 0.100 \\
\hline \multirow[t]{8}{*}{ trans-4-GG crocin } & 0.78 & 46,612 & 0.342 & \multirow[t]{8}{*}{0.9999} & 8.56 & 0.052 \\
\hline & 1.56 & 94,230 & 0.515 & & 8.56 & 0.057 \\
\hline & 3.13 & 185,125 & 0.104 & & 8.56 & 0.064 \\
\hline & 6.25 & 370,392 & 1.038 & & 8.56 & 0.000 \\
\hline & 12.5 & 737,008 & 0.592 & & 8.57 & 0.000 \\
\hline & 25 & $1,542,668$ & 0.879 & & 8.57 & 0.107 \\
\hline & 50 & $2,996,811$ & 0.230 & & 8.57 & 0.057 \\
\hline & 100 & $5,814,605$ & 0.167 & & 8.57 & 0.057 \\
\hline \multirow[t]{8}{*}{ trans-3-Gg crocin } & 0.31 & 25,326 & 0.149 & \multirow[t]{8}{*}{0.9999} & 8.97 & 0.061 \\
\hline & 0.63 & 51,050 & 0.674 & & 8.97 & 0.061 \\
\hline & 1.25 & 100,145 & 0.078 & & 8.98 & 0.061 \\
\hline & 2.5 & 200,421 & 1.042 & & 8.98 & 0.055 \\
\hline & 5 & 399,730 & 0.592 & & 8.98 & 0.067 \\
\hline & 10 & 840,876 & 0.881 & & 8.98 & 0.109 \\
\hline & 20 & $1,645,852$ & 0.223 & & 8.99 & 0.075 \\
\hline & 40 & $3,284,919$ & 0.090 & & 8.98 & 0.067 \\
\hline \multirow[t]{8}{*}{ cis-4-GG crocin } & 3.12 & 3517 & 1.363 & \multirow[t]{8}{*}{0.9999} & 9.78 & 0.056 \\
\hline & 6.25 & 6349 & 0.614 & & 9.76 & 0.000 \\
\hline & 12.5 & 14,124 & 0.848 & & 9.76 & 0.050 \\
\hline & 25 & 25,724 & 0.959 & & 9.76 & 0.062 \\
\hline & 50 & 49,984 & 0.700 & & 9.76 & 0.070 \\
\hline & 100 & 97,005 & 0.454 & & 9.76 & 0.000 \\
\hline & 200 & 187,596 & 0.276 & & 9.76 & 0.062 \\
\hline & 400 & 371,869 & 0.117 & & 9.77 & 0.057 \\
\hline \multirow[t]{8}{*}{ trans-2-gg crocin } & 3.12 & 6203 & 0.610 & \multirow[t]{8}{*}{1.0000} & 10.25 & 0.059 \\
\hline & 6.25 & 11,923 & 1.193 & & 10.23 & 0.089 \\
\hline & 12.5 & 23,244 & 0.658 & & 10.23 & 0.069 \\
\hline & 25 & 45,552 & 0.466 & & 10.23 & 0.049 \\
\hline & 50 & 90,122 & 0.675 & & 10.23 & 0.079 \\
\hline & 100 & 177,148 & 0.144 & & 10.23 & 0.099 \\
\hline & 200 & 356,131 & 0.563 & & 10.23 & 0.059 \\
\hline & 400 & 722,238 & 0.206 & & 10.23 & 0.099 \\
\hline \multirow[t]{8}{*}{ trans-crocetin } & 0.16 & 11,270 & 0.454 & \multirow[t]{8}{*}{1.0000} & 13.42 & 0.033 \\
\hline & 0.31 & 22,426 & 0.774 & & 13.42 & 0.033 \\
\hline & 0.63 & 44,264 & 0.218 & & 13.42 & 0.041 \\
\hline & 1.25 & 88,390 & 1.103 & & 13.43 & 0.037 \\
\hline & 2.5 & 176,108 & 0.601 & & 13.43 & 0.037 \\
\hline & 5 & 370,557 & 0.968 & & 13.43 & 0.045 \\
\hline & 10 & 728,893 & 0.221 & & 13.44 & 0.000 \\
\hline & 20 & $1,469,695$ & 0.071 & & 13.43 & 0.045 \\
\hline safranal & 0.16 & 6250 & 0.964 & 0.9996 & 14.05 & 0.035 \\
\hline & 0.31 & 11,433 & 1.114 & & 14.05 & 0.053 \\
\hline & 0.63 & 21,535 & 0.286 & & 14.06 & 0.063 \\
\hline & 1.25 & 41,788 & 1.005 & & 14.06 & 0.067 \\
\hline & 2.5 & 81,578 & 0.567 & & 14.07 & 0.035 \\
\hline & 5 & 169,766 & 0.989 & & 14.07 & 0.043 \\
\hline & 10 & 332,776 & 0.055 & & 14.07 & 0.043 \\
\hline & 20 & 669,921 & 0.042 & & 14.06 & 0.053 \\
\hline
\end{tabular}

$a * \mu \mathrm{g} / \mathrm{mL}, * *$ relative standard deviation. 


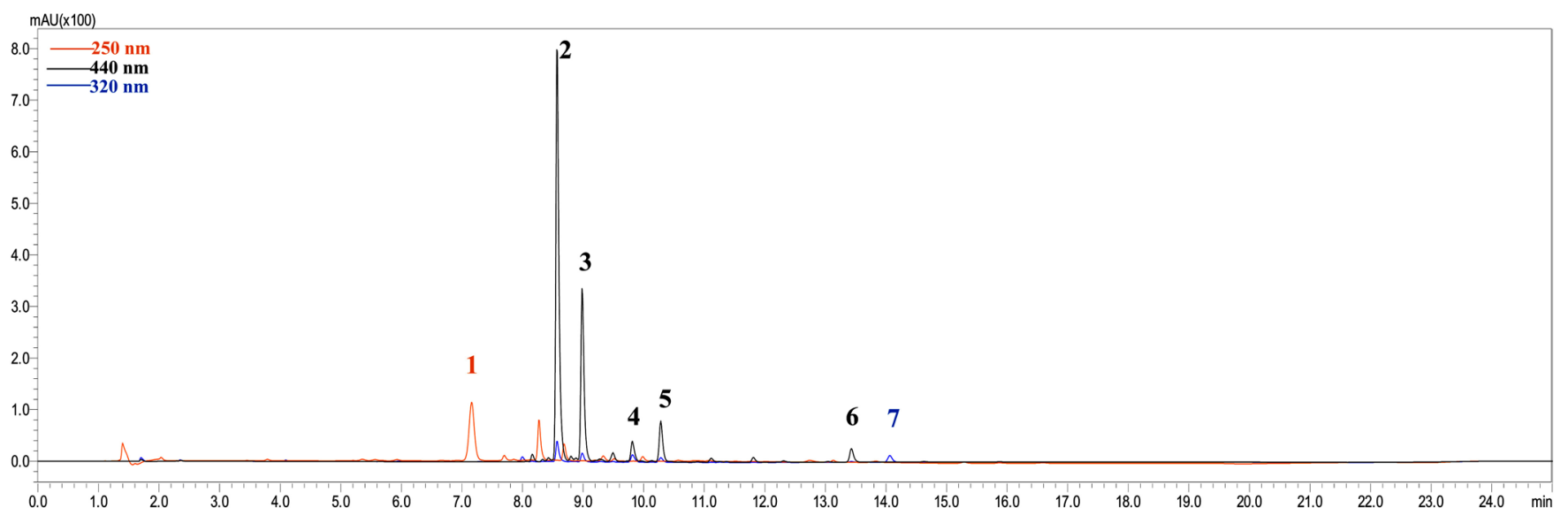

Figure 4. Kashmir saffron (C. sativus L.)-based botanical supplement (CSE) standardization by batch analysis $(n=3)$ by HPLC-PDA analysis. Representative chromatogram at wavelengths of $250 \mathrm{~nm}$ (compound 1), $440 \mathrm{~nm}$ (compound 2-6), and $320 \mathrm{~nm}$ (compound 7).

analysis was performed in triplicate in two concentration levels as 100 and $200 \mu \mathrm{g} / \mathrm{mL}(\% \mathrm{RSD},<1.0)$ for each analyte. The reproducibility was carried out to determine the content of each analyte in CSE. The samples were prepared in six concentration ranges $6.25-200 \mu \mathrm{g} / \mathrm{mL}$; analysis was performed five times with $\%$ RSD, $<1.2$ for the content of each analyte (Tables S1, S2, Supporting Information).

2.2.3.5. Recovery and Solution Stability. The average recovery of each analyte was found to be $90.36 \%$ (1), $82.49 \%$ (2), 86.55\% (3), 88.65\% (4), 90.78\% (5), 90.96\% (6), and $92.96 \%$ (7). It showed the accuracy of the method for targeted analytes in ambiguous matrices.

The solution stability was evaluated every $7 \mathrm{~h}$ with standard stock solutions and CSE. The chromatographic profile of the analyte in reference standards and sample solution did not exhibit any significant change over $42 \mathrm{~h}$ at autosampler stability. In addition, no significant decrease in total content in the sample extract over $42 \mathrm{~h}$ was observed at autosampler temperature (Figures S6 and S7 and Tables S3 and S4, Supporting Information).

2.2.4. HPLC-PDA Quantification of Apocarotenoids in CSE. The quantification of the developed method can be used for routine analysis of quality control (QC) and research laboratories. Herein, a reversed-phase approach for rapid matrix extraction for polar solvents was utilized to obtain chromatographic profiling and standardized CSE fingerprinting (Figure 4). This approach can also be applied to hyphenated techniques such as LC-MS/MS to confirm apocarotenoids and flavonoids in CSE. The CSE profile was generated in 10 batches $(n=3)$ to develop a robust method (Table 4$)$.

This was further confirmed by the untargeted identification of carotenoid and apocarotenoid from CSE by LC-MS/MS analysis in both negative and positive ionization scan modes. The compounds present in CSE samples were additionally confirmed from 3D information (UV-vis spectrum, Rt, and MS spectrum) (Table S5 and Figure S8, Supporting Information).

2.2.5. Assessment of Uncertainty. The expanded uncertainty of the method for quantifying compounds $(1-7)$ in CSE was calculated. The sources of uncertainty, which were considered, are the uncertainty associated with reproducibility, instrument operation, standard and sample weights, and its dilutions (Figure S9, Supporting Information). The observed significant influence in the combined uncertainty comes from standard preparation. This is due to the number of sources of uncertainty (purity of standard, weight, calibration, and dilution) and concentration of the standard and sample at a level of $\mathrm{mg} / \mathrm{mL}$. In the contribution of uncertainty associated with validation data, the low influence of recovery uncertainty gives an idea for the good accuracy of the method. For the EURACHEM guideline and method validation approach, the expanded uncertainty $U_{\exp }$ at a $95 \%$ confidence level was obtained by multiplying the combined uncertainties by the coverage factor $(K=2)$. The results of the seven compounds and their overall uncertainty are about $9.22 \pm 1.34,9.49 \pm$ $1.37,1.46 \pm 0.21,0.35 \pm 0.05,0.57 \pm 0.08,0.053 \pm 0.008$, and $0.047 \pm 0.007 \%$, for apocarotenoid quantification (Table 5).

2.3. HPTLC Characterization of Apocarotenoids and Flavonoids in CSE $(n=10)$. A simple and rapid HPTLC fingerprinting was performed for apocarotenoids (1-3) and flavonoids $(8)$ in the batch analysis of CSE samples $(n=10)$. All four marker compounds (1-3 and 8) showed major bands at $366 \mathrm{~nm}$ and under white light after derivatization with the NP-PEG reagent. This method was found to be useful when it was applied to the standardized extract and botanical supplement of KCS stigmas. The apocarotenoids (1-3) with flavonoid (8) were observed prominently in all CSE samples (Figure 5).

After derivatization with the NP-PEG reagent, the yellowcolored and dark brownish bands showed confirmed major compounds (1-3 and 8) at white light and $366 \mathrm{~nm}$ in CSE samples using Camag TLC visualizer 2. Thus, this method was found to be rapid and useful for visual aid identification of stigmas and its extracts in the QC and processing of KCS.

2.4. LC-MS/MS-Based Identification of Apocarotenoids and Flavonoids from KCS and Its Botanical Supplements. An untargeted identification of bioactive constituents from CSE samples was achieved by HPLCbased ESI-MS/MS analysis in both negative and positive ionization modes. These compounds were found from the classes of apocarotenoids and flavonoids mainly. In addition, the structural correlation and confirmation were investigated based on possible fragmentation characteristics of compounds and the information from the literature ${ }^{30,33-40}$ (Figure 6).

Recently, the identification of picrocrocin and related compounds has gained much attention. Picrocrocin (1) is a monoterpene precursor of an aroma compound safranal (7) which forms due to the cleavage of carotenoids and is known 
我

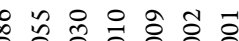

○

$+1+1+1+1+1+1$

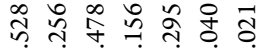

๙ุ

aे

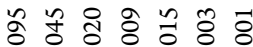

公 $+1+1+1+1+1+$

๗ี

$\infty$

$\approx$ ก

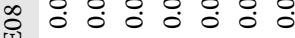

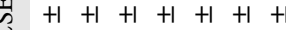

\# $\approx$ స

$\infty$ a

ำ

人

空 $+1+1+1+1+1+1+1$

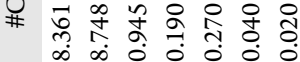

○

우유ำ

贸 $+1+1+1+1+1+1+$

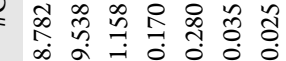

ปี

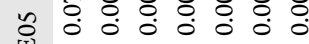

留 $+1+1+1+1+1+1$

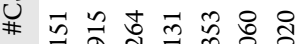

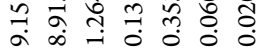

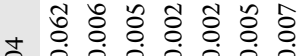

岳 $+1+1+1+1+1$

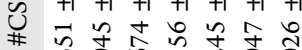

๙ุ

๓

至 $+1+1+1+1+1+1+1$

\#

๙े

(

.

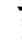

Table 5. Contributions of the Combined Uncertainties $\left(U_{\text {comb }}\right)$ with Expanded Uncertainty $\left(U_{\text {exp }}\right)$ at the $95 \%$ Confidence Level with $K=2$, Coverage Factor According to the EURACHEM Guide

\begin{tabular}{|c|c|c|c|c|}
\hline $\begin{array}{l}\text { sr. } \\
\text { no. }\end{array}$ & analyte & $\begin{array}{l}\text { mean average } \\
\text { content }(\%)\end{array}$ & $\begin{array}{l}U_{\text {comb }} \\
(\%)\end{array}$ & $\begin{array}{c}U_{\exp }(\%) \\
(K=2,95 \%)\end{array}$ \\
\hline 1 & picrocrocin & 9.22 & 0.67 & 1.34 \\
\hline 2 & $\begin{array}{l}\text { trans-4-GG } \\
\text { crocin }\end{array}$ & 9.49 & 0.69 & 1.37 \\
\hline 3 & $\begin{array}{l}\text { trans-3-Gg } \\
\text { crocin }\end{array}$ & 1.46 & 0.11 & 0.21 \\
\hline 4 & $\begin{array}{l}\text { cis-4-GG } \\
\text { crocin }\end{array}$ & 0.35 & 0.03 & 0.05 \\
\hline 5 & $\begin{array}{l}\text { trans-2-gg } \\
\text { crocin }\end{array}$ & 0.57 & 0.04 & 0.08 \\
\hline 6 & trans-crocetin & 0.053 & 0.004 & 0.008 \\
\hline 7 & safranal & 0.047 & 0.0035 & 0.007 \\
\hline
\end{tabular}

as apocarotenoids. Due to the polar nature, these apocarotenoids elute early from Rt $2.9-7.12$ min with a characteristic UV wavelength $(208-286 \mathrm{~nm})$. These apocarotenoids were illustrated as AP1-AP4, AP6-AP17, and AP36 in Figure 6. The minor compounds, kaempferol derivatives, were found at Rt of 3.9, 7.8, and 11.8 min identified as FL5, FL19, and FL34, respectively, in CSE with characteristic UV max (320-350 $\mathrm{nm}$ ) with distinct polar $R_{f}$ in HPTLC analysis.

The major group identified is apocarotenoids as crocin derivatives and crocetins with the sugar moieties [like $\beta$-Dglucose $(\mathrm{g}), \beta$-D-gentiobiose $(\mathrm{G}), \beta$-D-neapolitanose $(\mathrm{n})$, and $\operatorname{tri}-\beta$-D-glucose $(\mathrm{t})]$. The isomeric forms of crocins were identified at Rt 7.5-11 min with comparative elution of crocetins after $12 \mathrm{~min}$. Mainly sodium and potassium adducts separated by $16 \mathrm{Da}$ were found with precursors in the crocin analysis as higher energy gives suitable product ions. Due to the complexity of the crocin structure and its isomeric forms, the MS/MS analysis based on polarity, the conversion of crocin to crocetin, ester-sugar moieties, and reference standards was used to ascertain these lesser stable compounds. The peaks were assigned and ascertained as CR18 and CR20CR35 by ESI-MS/MS (Figure S10, Supporting Information).

Thus, the structure of 36 compounds present in the standardized extract of $C$. sativus was fully or partially characterized using the combined interpretation of the Rt, $R_{f}$, UV spectra, precursor ion, and fragmentation patterns of the compounds obtained by HPLC-PDA, HPTLC, and MS/MS analyses (Table 6). These data were compared with experimental and literature data, those for the flavonoids and apocarotenoids present in Crocus species (SR2, Supporting Information for reviewers)..$^{30,33-40}$

2.5. MS/MS Characterization and Fragmentation of Compounds (1-7) in HPLC Analysis. The primary composition of CSE comprises compounds (1-7) detected at Rt 7.172, 8.530, 8.925, 9.446, 9.786, 10.259, and $14.146 \mathrm{~min}$ as peaks AP17, CR22, CR23, CR24, CR26, CR28, CR29, and AP36, respectively, from TIC data. These seven apocarotenoids were further characterized by MS/MS analysis to study their fragmentation pattern based on the precursor and product ions.

Compound (1) picrocrocin showed $m / z 331.3[\mathrm{M}+\mathrm{H}]^{+}$as a prominent ion which on fragmentation gets converted into safranal (7) $m / z 151.0$ (loss of one sugar molecule, $180 \mathrm{Da}$ ), which further showed the loss of $\left(\mathrm{C}_{4} \mathrm{H}_{6} \mathrm{O}\right) \mathrm{m} / z$ 81.4. Similarly, compound (7) which showed fragmentation gives two major 

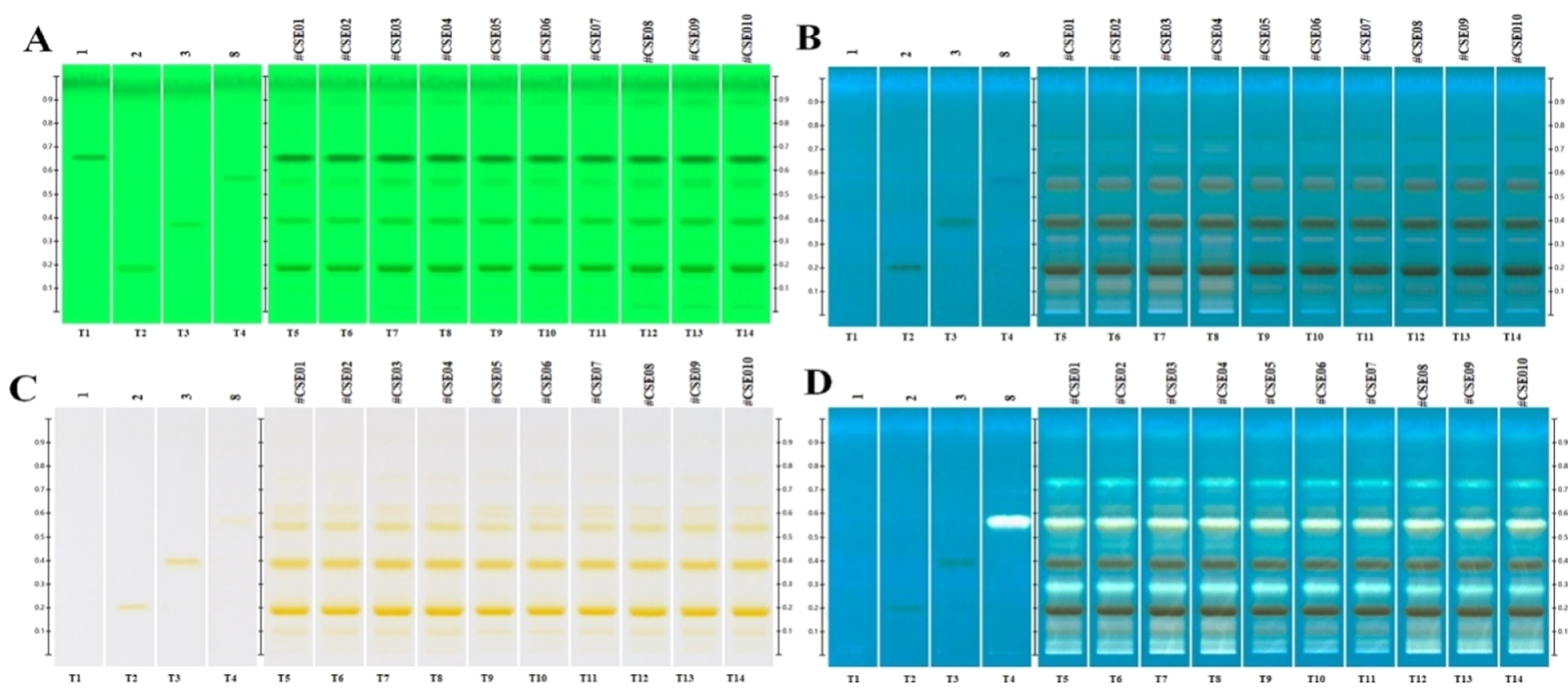

Figure 5. HPTLC fingerprinting of the stigma-based botanical supplement from KCS $(n=10)$ with reference standards under UV $254 \mathrm{~nm}$ (A), under UV $366 \mathrm{~nm}$ (B), under white light after derivatization (C), and under $366 \mathrm{~nm}$ after derivatization (D). Track details: T1-T4: reference standards, where picrocrocin (1), trans-4-GG-crocin (2), trans-3-Gg-crocin (3), and kaempferol-3-O- $\beta$-sophoroside (8), and T5-T14: samples of stigma-based botanical supplements (CSE).

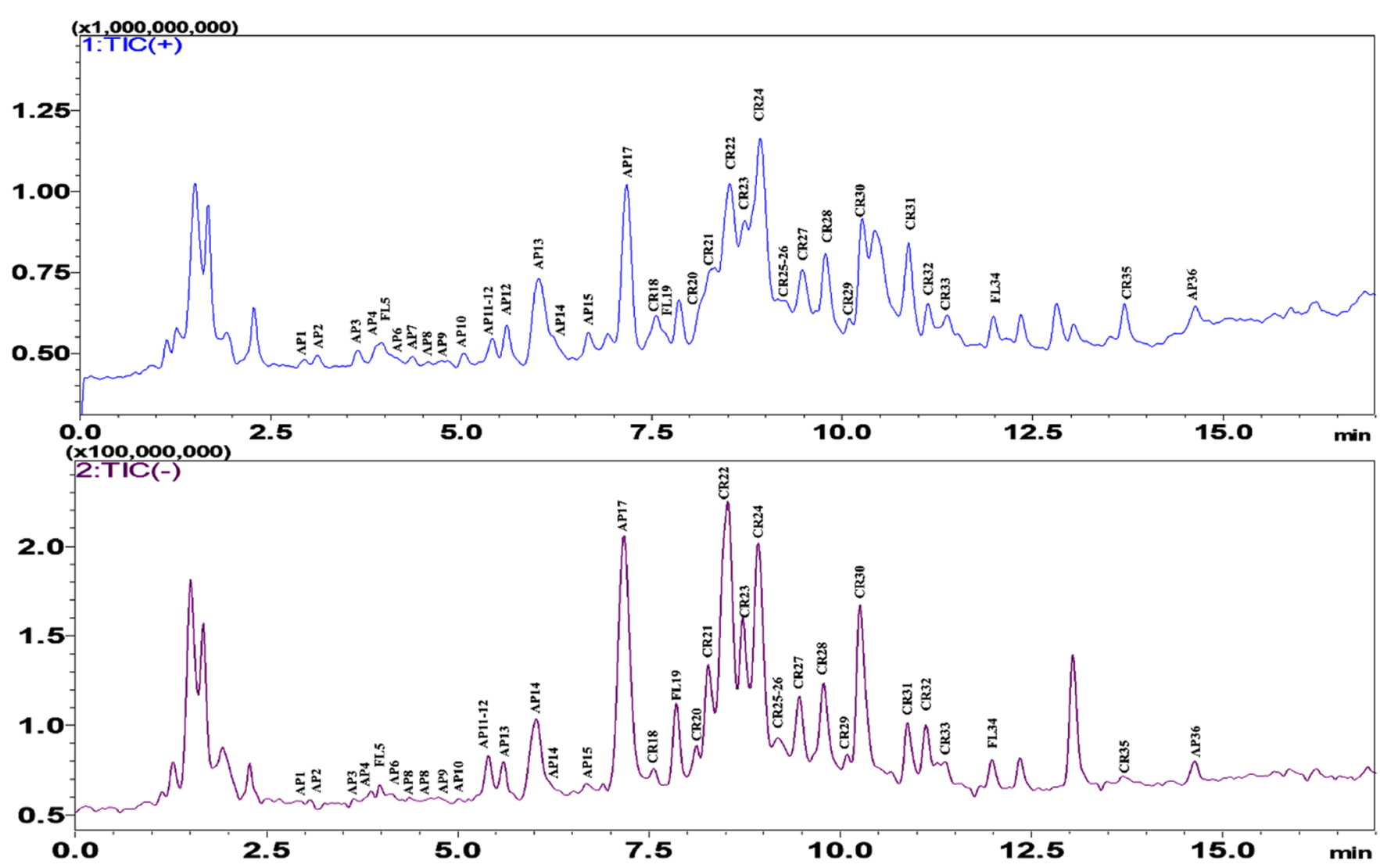

Figure 6. LC-MS/MS TIC of 36 compounds from apocarotenoids and flavonoids from KCS and its botanical supplements in the positive and negative mode.

fragments at $\mathrm{m} / z 123.1$ (loss of CO molecule, $28 \mathrm{Da}$ ) and $\mathrm{m} / z$ 81.0 (loss of $\mathrm{C}_{4} \mathrm{H}_{6} \mathrm{O}$ molecule, $70 \mathrm{Da}$ ) (Figure 7A,B).

The crocins and their derivatives $(2-6)$ showed characteristic fragmentation with loss of sugar moieties in MS/MS analysis. Compound (2) trans-4-GG-crocin fragmentation with $\mathrm{m} / z$ 975.4 was led by three major fragment ions, $[\mathrm{M}-\mathrm{H}]^{-}, \mathrm{m} /$ $z 651.25$ (loss of a gentiobiose sugar moiety $324 \mathrm{Da}$ ), and $[\mathrm{M}-2 \mathrm{Gent}-\mathrm{H}]^{-}, m / z 327.20$ (loss of both gentiobiose sugar moieties, each $324 \mathrm{Da}$ ). Compound (3) trans-3-Gg-crocin also showed characteristic $\mathrm{m} / z 814.8$ followed by removal of a gentiobiose sugar moiety $(324 \mathrm{Da})$ at $\mathrm{m} / z 651.25$ with subsequent removal of a sugar molecule $\left(162 \mathrm{Da}, \mathrm{C}_{6} \mathrm{H}_{10} \mathrm{O}\right)$ 
Table 6. Summary of Chemical Constituents Identified in the Standardized Botanical Supplement by LC-MS/MS

\begin{tabular}{|c|c|c|c|c|c|c|c|c|c|}
\hline \multirow[b]{2}{*}{ sr.no. } & \multirow{2}{*}{$\begin{array}{l}\text { retention time } \\
\left(R_{\mathrm{t}}\right)\end{array}$} & \multirow[b]{2}{*}{$R_{f}$} & \multirow[b]{2}{*}{$(\lambda \max )^{a}$} & \multirow{2}{*}{$\begin{array}{c}\text { peak } \\
\text { number }\end{array}$} & \multirow[b]{2}{*}{$\mathrm{MF}^{b}$} & \multirow[b]{2}{*}{$\mathrm{MW}^{c}$} & \multicolumn{2}{|c|}{$m / z$ observed } & \multirow[b]{2}{*}{ references } \\
\hline & & & & & & & +ve mode & -ve mode & \\
\hline 1 & 2.943 & & 208 & AP1 & unknown & & 349,367 & 345,355 & \\
\hline 2 & 3.115 & & 212 & $\mathrm{AP} 2$ & unknown & & 348,370 & & \\
\hline 3 & 3.640 & & 225,262 & AP3 & $\mathrm{C}_{16} \mathrm{H}_{24} \mathrm{O}_{8}$ & 344 & 345,367 & & 30 \\
\hline 4 & 3.866 & & 231,286 & $\mathrm{AP} 4$ & $\mathrm{C}_{16} \mathrm{H}_{28} \mathrm{O}_{8}$ & 348 & 371,387 & 391 & 30 \\
\hline 5 & 3.982 & & & FL5 & kaempferol-3.7.4'-triglucoside & 773 & 773,795 & 771,817 & $30,35,36$ \\
\hline 6 & 4.121 & & 238 & AP6 & $\mathrm{C}_{20} \mathrm{H}_{30} \mathrm{O}_{13}$ & 478 & 501 & 523 & 30 \\
\hline 7 & 4.367 & & 241 & $\mathrm{AP7}$ & $\mathrm{C}_{20} \mathrm{H}_{30} \mathrm{O}_{13}$ & 478 & 501 & & 30 \\
\hline 8 & 4.648 & & 245 & AP8 & unknown & 434 & 435,467 & & \\
\hline 9 & 4.821 & & 245 & AP9 & $\mathrm{C}_{20} \mathrm{H}_{30} \mathrm{O}_{13}$ & 332 & 355,371 & 377 & \\
\hline 10 & 5.013 & & 242 & AP10 & $\left(\mathrm{C}_{16} \mathrm{H}_{26} \mathrm{O}_{8}\right)$ & 346 & $369,385,410$ & 391,417 & 30 \\
\hline 11 & 5.400 & & 249 & AP11-12 & $\mathrm{C}_{14} \mathrm{H}_{20} \mathrm{O}_{8}$ & 316 & $355,317,339$ & 361,429 & 30 \\
\hline 12 & 5.596 & & 248 & AP13 & $\mathrm{C}_{22} \mathrm{H}_{36} \mathrm{O}_{12}$ & 492 & 515 & 537 & 30 \\
\hline 13 & 6.019 & & 248 & AP14 & unknown & 360 & 383 & 473 & \\
\hline 14 & 6.680 & & 247 & AP15 & unknown & 330 & 353 & $376,365,443$ & \\
\hline 15 & 6.901 & & 254 & AP16 & unknown & 343 & 366,406 & 387 & \\
\hline 16 & 7.172 & 0.63 & 250 & AP17 & picrocrocin & 330 & $353,369,399$ & $376,365,443$ & 30,36 \\
\hline 17 & 7.563 & & 244,262 & CR18 & unknown & 453 & 454,476 & $565,497,566$ & \\
\hline 18 & 7.856 & 0.53 & 442 & FL19 & kaempferol-3-sophoroside & 610 & 611,633 & $609,610,655$ & $30,38,39$ \\
\hline 19 & 8.119 & & 439 & CR20 & trans-5-tG-crocin & 1138 & $329,635,1161$ & 1183 & 35,38 \\
\hline 20 & 8.273 & & 418,436 & CR21 & trans-5-nG-crocin & 1138 & $329,635,1161$ & 1183 & 28,30 \\
\hline 21 & 8.530 & 0.16 & 440,463 & CR22 & trans-4-GG-crocin & 976 & $329,681,999$ & $\begin{array}{c}723,533 \\
1021\end{array}$ & $\begin{array}{l}28-30,36,37 \\
40\end{array}$ \\
\hline 22 & 8.725 & & 439,462 & CR23 & unknown & & 794,816 & & \\
\hline 23 & 8.925 & 0.33 & 437 & $\mathrm{CR} 24$ & trans-3-Gg-crocin & 814 & $837,832,814,815$ & $859,860,849$ & $28-30,36,40$ \\
\hline 24 & 9.28 & & 440,463 & $\mathrm{CR} 25$ & cis-5-tG-crocin & 1138 & & 1138 & 48 \\
\hline 25 & 9.446 & & 436 & CR26 & trans-2-G-crocin & 652 & $329,547,675,837$ & $697,765,249$ & $28,30,37,39,40$ \\
\hline 26 & 9.516 & & 434 & $\mathrm{CR} 27$ & cis-5-nG-crocin & 1138 & $329,625,837,1139$ & & 30,43 \\
\hline 27 & 9.786 & & 431 & CR28 & cis-4-GG-crocin & 976 & $\begin{array}{l}329,508,697,735 \\
999\end{array}$ & $\begin{array}{l}651,975 \\
1089\end{array}$ & $30,37,40,43$ \\
\hline 28 & 10.259 & & 434,457 & CR29 & trans-2-gg-crocin & 652 & $329,651,675,691$ & $697,651,698$ & $30,38-40$ \\
\hline 29 & 10.279 & & 433,456 & CR30 & cis-3-Gg-crocin & 814 & $329,837,675$ & $697,765,859$ & $28,30,33,37$ \\
\hline 30 & 10.880 & & 252,427 & CR31 & cis-2G-crocin & 652 & $329,541,675$ & $563,631,517$ & $30,37,40$ \\
\hline 31 & 11.122 & & 251,426 & CR32 & trans-1-g-crocin & 490 & $554,329,513$ & $535,525,681$ & $28,30,40$ \\
\hline 32 & 11.370 & & 255,432 & CR33 & cis-2-gg-crocin & 652 & $274,329,675$ & & $28,30,39$ \\
\hline 33 & 11.984 & & & FL34 & dihydro kaempferol & 288 & 288,330 & 286,354 & \\
\hline 34 & 13.486 & & 425,450 & CR35 & trans-crocetin & 328 & 329,594 & & $28,30,36,43$ \\
\hline 35 & 14.146 & & 265 & AP36 & safranal & 150 & 151,192 & & $28,30,36,39$ \\
\hline
\end{tabular}

further as the trans-crocetin $(6)$ ion as $m / z 327.1[\mathrm{M}-\mathrm{H}]^{-}$ which is unanimously the most prominent ion observed among all crocins. Compound (5) trans-2-gg-crocin with the precursor ion at $\mathrm{m} / \mathrm{z} 651.3$ in the negative mode showed loss of the gentiobiose moiety ( $324 \mathrm{Da}$ ) with two other fragments as $\mathrm{m} / z$ 283.7 (loss of the $-2 \mathrm{CO}_{2}$ group) and $\mathrm{m} / z 239.4$ (loss of the $\mathrm{CO}_{2}$ group) in MS/MS fragmentation. The compound (4) was found unstable as cis-4-GG-crocin with a similar precursor and product ions, suggesting a fragmentation pattern in accordance with trans-4-GG-crocin, which is a more stable form. Compound (6) trans-crocetin was the most prominent and comparatively nonpolar fragment observed with all crocins, which showed four fragments at $\mathrm{m} / z 283.3$ (loss of $\mathrm{CO}_{2}$ groups, $44 \mathrm{Da}$ ), $m / z 268.9$ (loss of $\mathrm{CO}_{2}-\mathrm{CH}_{3}, 58 \mathrm{Da}$ ), and $m / z 239.4$ (loss of the $2 \mathrm{CO}_{2}$ group) from its precursor $m$ / $z 327.3$ in these data. The studied fragmentation pattern is represented in Figure $7 \mathrm{C}-\mathrm{G}$.

\section{CONCLUSIONS}

Kashmir saffron (C. sativus L., KCS), a well-known food condiment, is an ideal lead for a botanical supplement with its unique cultivated supply and rich heritage. Additionally, the Indian traditional medicinal systems and modern scientific data validate this botanical's efficacy in brain health. Thus, the present study and data for the validated HPLC-PDA method with HPTLC and LC-MS/MS can be used to standardize this popular food condiment in the botanical-health supplement segment. These methods were applied to characterize apocarotenoids and flavonoids in KCS and its standardized botanical supplement (CSE).

An HPTLC analytical approach with the precise detection mode was helpful in the identification of picrocrocin and flavonoids as distinct patterns in fingerprinting for flower parts and CSE. The rapid HPLC-PDA method for the simultaneous quantification of KCS apocarotenoids was robust, precise $(<5.0 \%)$, linear $\left(R^{2}>0.99\right)$, and accurate $(80-110 \%)$ as per the single-laboratory validation data. This HPLC-PDA method 

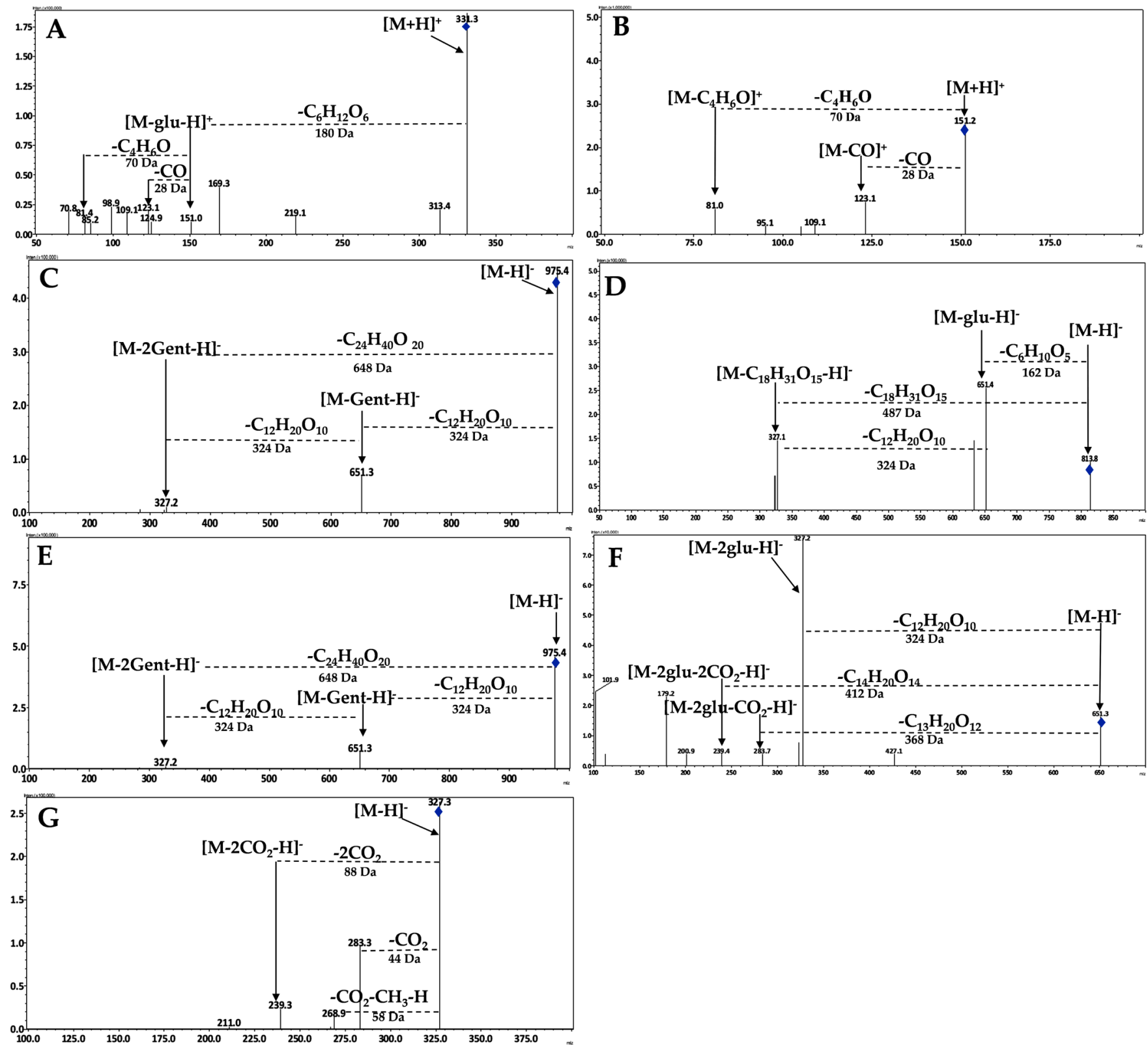

Figure 7. Positive and negative ESI-MS/MS spectra highlighting the main fragments of detected peaks as (AP17) picrocrocin and (AP36) safranal (A,B) with (CR22) trans-4-GG crocin, (CR24) trans-3-Gg crocin, (CR28) cis-4-GG crocin, (CR29) trans-2-gg crocin, and (CR35) trans-crocetin $(C-G)$, respectively. In the case of these apocarotenoids, the fragmentation patterns were in accordance with those proposed by refs 26 and 30 .

was found to be sensitive and specific for routine analysis of apocarotenoids, measuring uncertainty. The results showed that uncertainty associated with the KCS and CSE analysis has more influence of the reference standard and sample preparation than other HPLC methodology factors. These findings are in accordance with the study's aim for precise and reproducible results of targeted KCS apocarotenoids compared with different solvent systems. Furthermore, a specific MS/MS fragmentation-based rapid screening with detailed structural identification of 36 compounds is helpful in the CSE composite profile. Data obtained by UV-based HPTLC and HPLC-PDA methods were found to be a precise approach to establish a QC method for KCS and its extract-based botanical health supplements.

Hence, the results suggest that this validated analytical method can be applied to quantify apocarotenoids obtained from the stigma extract of C. sativus L. in different preclinical and clinical studies. The absorption, distribution, metabolism, and excretion of these KCS constituents (pharmacokinetics), along with their effects (pharmacodynamics), could be studied quantitatively and qualitatively with these robust analytical investigation techniques.

\section{MATERIALS AND METHODS}

4.1. Plant Material and Extract. Samples were collected from Srinagar (Jammu and Kashmir), India, for this study. The sample was identified and authenticated from the Botanical Survey of India (Jodhpur), with voucher specimen (BSI/ AZRC/1.12012/Tech./19-20/(PI.Id)/671). The herbarium specimens and samples were deposited in the Botanical Repository of Pharmanza Herbal Pvt. Ltd., Gujarat, India (Table 7). The dried stigmas were grounded to a coarse 
Table 7. Locations, Flower Parts, and Accession Numbers of Samples of Kashmir Saffron (C. sativus)

\begin{tabular}{cccc} 
sr. no. & flower part & accession no. ${ }^{a}$ & location (district) \\
1 & stigma & $2101-\mathrm{A}$ & Pampore (Pulwama) \\
2 & stamen & $2101-\mathrm{B}$ & Pampore (Pulwama) \\
3 & tepal & $2101-\mathrm{C}$ & Pampore (Pulwama) \\
4 & stigma & $2102-\mathrm{A}$ & Dawlatpura (Budgam) \\
5 & stamen & $2102-\mathrm{B}$ & Dawlatpura (Budgam) \\
6 & tepal & $2102-\mathrm{C}$ & Dawlatpura (Budgam) \\
7 & stigma & $2103-\mathrm{A}$ & Sampora (Srinagar) \\
8 & stamen & $2103-\mathrm{B}$ & Sampora (Srinagar) \\
9 & tepal & $2103-\mathrm{C}$ & Sampora (Srinagar) \\
10 & stigma & $2104-\mathrm{A}$ & Poochal (Kishtwar) \\
11 & stamen & $2104-\mathrm{B}$ & Poochal (Kishtwar) \\
12 & tepal & $2104-\mathrm{C}$ & Poochal (Kishtwar) \\
${ }^{3}$ Accession numbers. & & \\
\hline
\end{tabular}

powder $(200 \mathrm{~g})$ and extracted with ethanol-water at $40^{\circ} \mathrm{C}$ for $3 \mathrm{~h}$. Extraction was repeated twice, followed by distillation of the solvent below $50{ }^{\circ} \mathrm{C}$ with yield $(20 \%)$. The extract powder (CSE) obtained was stored in an amber-colored bottle below $-4{ }^{\circ} \mathrm{C}$ after distillation. The CSE $(110 \mathrm{~g})$ was suspended in water, followed by partitioning with hexane-ethyl acetate. Furthermore, the hexane-ethyl acetate fraction (12 g) compound 1 (28 mg) and compound $6(34 \mathrm{mg})$ were isolated and characterized by nuclear magnetic resonance (NMR) and MS/MS analysis (SR1, Supporting Information for reviewers). ${ }^{27,28}$

4.2. Chemicals and Standards. Compounds used in this study are picrocrocin (1), trans-4-GG-crocin (2), trans-3-Ggcrocin (3), cis-4-GG-crocin (4), trans-2-gg-crocin (5), transcrocetin (6), safranal (7), kaempferol 3-O- $\beta$-sophoroside (8), kaempferol-O-glucoside (9), and quercetin-3,4'-di-O-glucoside (10) (Figure 2). Compounds (1 and 6) were isolated in-house using previously reported extraction and column chromatographic methods and further characterized by ${ }^{1} \mathrm{H}$ and ${ }^{13} \mathrm{C}$ NMR, LC-MS/MS, and HPLC-PDA. The reference standards were procured from the following suppliers: compounds (23) were procured from Chromadex (CA, USA) and PhytoLab, (Germany), respectively. Compound 7 and compounds 8-9 and 11 were procured from Sigma-Aldrich (St. Louis, USA) and Chemfaces (Hubei, China), and USP (USA), respectively. Compounds 4-5 were isolated in-house at CSIR-IIIM laboratory (Jammu, India) as per previous reports. ${ }^{25}$ The purity of reference standards was checked by analyzing highconcentration $(1 \mathrm{mg} / \mathrm{mL})$ solution by HPLC-PDA and was found pure $(>90 \%)$. Acetonitrile, methanol, water (JT Baker, India), and formic acid, MS grade (Fluka, Honeywell, India), were used in the LC-MS/MS study.

4.3. Preparation of Standard Solutions. For HPTLC analysis, compounds 1-3 and 8-10 (1 mg/mL) were prepared with DMSO/methanol $(2: 8 v / v)$, and for HPLCPDA and LC-MS/MS analysis, stock solution of standards (1-3) $0.5 \mathrm{mg} / \mathrm{mL},(4-5) 1.0 \mathrm{mg} / \mathrm{mL}$, and $(6-7)(0.1 \mathrm{mg} /$ $\mathrm{mL})$ were prepared and stored in amber-colored glass vials at $-4{ }^{\circ} \mathrm{C}$ until analysis.

4.4. Sample Preparation of Flower Parts for HPTLC Analysis. Dried and powdered crude materials of KCS stigma, stamen, and tepal $(1 \mathrm{~g})$ were kept in an HPLC-grade methanol amber-colored volumetric flask for sonication for $10 \mathrm{~min}$ at room temperature. After sonication, samples were centrifuged at $5000 \mathrm{rpm}$ for $5 \mathrm{~min}$, and the supernatant was collected, filtered through a $0.22 \mu \mathrm{m}$ filter, and used for HPTLC analysis.

4.5. Sample Preparation of CSE for HPTLC, HPLCPDA, and LC-MS/MS Analysis. Accurately weighed CSE $(1.0 \mathrm{mg} / \mathrm{mL})$ was transferred in an amber-colored volumetric flask, DMSO/methanol (2:8) was added, and it was sonicated for $10-15 \mathrm{~min}$ followed by centrifugation at $5000 \mathrm{rpm}$ for 5 $\min (1000 \mu \mathrm{g} / \mathrm{mL})$. The working solution of CSE was prepared with the dilution of methanol $(200 \mu \mathrm{g} / \mathrm{mL})$ used for HPLC-PDA and MS/MS analysis. For HPTLC analysis, the stock $(10 \mathrm{mg} / \mathrm{mL})$ and working solution of CSE $(1000 \mu \mathrm{g} /$ $\mathrm{mL}$ ) were prepared with the same method. All the samples were stored below $-4{ }^{\circ} \mathrm{C}$ in the dry and solution form during the study.

4.6. Instrumentation and Experimental Conditions. 4.6.1. HPTLC Analysis. Samples were applied in the $8 \mathrm{~mm}$ band using a Hamilton syringe $(100 \mu \mathrm{L})$ (Hamilton, Switzerland) on the precoated silica gel plate $60 \mathrm{~F}_{254}$ (size $20 \times 10 \mathrm{~cm} \times 0.2 \mathrm{~mm}$ thickness and particle size 5-6 $\mu \mathrm{m}$ ) (Merck, Darmstadt, Germany) using the TLC applicator Linomat 5 (Camag, Switzerland) with vision CATS software (version 3.0.20196.1). The application positions ( $X$ and $Y$ ) were 20 and $8 \mathrm{~mm}$, respectively, with a development of $80 \mathrm{~mm}$ in length. The solvent system used ethyl acetate: methanol: water $(9: 2: 1.5) v / v / v)$ followed by TLC development using a $20 \times 10 \mathrm{~cm}$ twin trough chamber. The optimized chamber saturation time for the solvent system was $20 \mathrm{~min}$, at the temperature $25 \pm 2{ }^{\circ} \mathrm{C}$. The plates were dried and were analyzed at 254 and $366 \mathrm{~nm}$ and white light before and after derivatization with the NP-PEG reagent in TLC visualizer 2 (Camag, Switzerland). ${ }^{33}$

4.6.2. High-Performance Liquid Chromatography-Photodiode Array-Mass Spectrometry. Chromatography was achieved using a Shimadzu N-Series XS Al-PDA HPLC system. Chromatographic separation was carried out on a Phenomenex Luna, $5 \mu \mathrm{m} \mathrm{C18} \mathrm{(2)} 100 \AA$ Å column $(150 \times 4.6$ $\mathrm{mm} \times 5 \mu \mathrm{m})$ at $30{ }^{\circ} \mathrm{C}$. The mobile phase consisted of $0.1 \%$ formic acid in water (A) and acetonitrile (B). The gradient condition was $0.01-5.00 \mathrm{~min}, 20-20 \% \mathrm{~B}$; $5.00-13.00 \mathrm{~min}$, $20-80 \% \mathrm{~B} ; 13.00-18.00 \mathrm{~min}, 80-80 \% \mathrm{~B}$; and $18.00-21.00$ $\min , 80-20 \% \mathrm{~B}$. The run time was $25 \mathrm{~min}$, followed by a flow rate of $1.0 \mathrm{~mL} / \mathrm{min}$ and an injection volume of $10 \mu \mathrm{L}$, and the detection wavelengths are $250 \mathrm{~nm}$ for (1), $320 \mathrm{~nm}$ for (7), and $440 \mathrm{~nm}$ for $(2-6)$.

4.6.3. Liquid Chromatography Triple-Quadrupole Mass Spectrometry (LC-MS/MS) Analysis. Qualitative analysis was performed on Shimadzu Nexera X2 (Shimadzu Tech., Kyoto, Japan) consisting of a quaternary pump (LC-30AD), autosampler (SIL-30AC), column oven (CTO-20 AC), and diode array detector (SPD-M20A) and coupled with LCMS8045 (Shimadzu Tech., Kyoto, Japan). The TQ-MS/MS was equipped with a thermally assisted ESI source with an outlet of the PDA detector connected to a splitter (Split; ratio 4:1) with the same chromatographic conditions with a precolumn (Phenomenex security guard ULTRA with C18 cartridge). The autosampler temperature was set at $15{ }^{\circ} \mathrm{C}$ with a flow rate of $1.0 \mathrm{~mL} / \mathrm{min}$ and an injection volume of $10 \mu \mathrm{L}$ for total ion chromatogram (TIC) acquisition. Mass analyses were performed for precursor ion scan in both positive- and negative-ion modes at a scan speed of $2000 \mathrm{u} / \mathrm{sec}$ with an interface temperature of $300{ }^{\circ} \mathrm{C}$. The desolvation line and heat block temperatures were set to 250 and $300{ }^{\circ} \mathrm{C}$, respectively. The gas flows for nebulizing, heating, and drying gas were kept 
at flow 10,3 , and $10 \mathrm{~L} / \mathrm{min}$, respectively. The sample (CSE) was analyzed in the $\mathrm{Q} 1$ scan mode, where the scan range was kept at $100-2000 \mathrm{~m} / z$. The MS/MS fragmentation of compounds (1-7) was carried out in an ESI interface using the MRM mode. The mass resolution was set at 0.05 full width at half-maximum with resolving power $\mathrm{Rp}$ (1000-3000). The quadruple setting was set as voltage Q1 RF gain: 4998 Q1 RF offset 4990 and Q1 post-rod bias: $-5.0 \mathrm{~V}$ CID CELL exit lens: -4.0 V. Datawere analyzed using Lab Solution software (Version 6.80). ${ }^{28,34,41-43}$

4.7. Single-Laboratory-Based Validation Data of HPLC-PDA. 4.7.1. System Suitability and Selectivity. The system suitability was demonstrated for a chromatographic system with retention time (Rt), peak area, peak shape USP tailing factor, theoretical plates $(N)$, capacity factor $\left(k^{\prime}\right)$, resolution (Rs), and the relative retention time (RRt) of each analyte. The selectivity of the analytical method determines the targeted analytes in the multicomponent matrix without the interference of other compounds which was determined by injecting individual reference standards. ${ }^{44}$

4.7.2. Specificity and Linearity. Specificity and linearity were assessed by the method's accurate and specific analysis of targeted analytes in the range of the method response determining the spectral similarity peak resolution and purity using a PDA detector. The linearity was demonstrated in the range of $0.78-100 \mu \mathrm{g} / \mathrm{mL}$ for standards $1-2,3.12-400 \mu \mathrm{g} /$ $\mathrm{mL}$ for standards $4-5,0.16-20 \mu \mathrm{g} / \mathrm{mL}$ for standards $6-7$, and $0.31-40 \mu \mathrm{g} / \mathrm{mL}$ for standard 3 with eight concentration levels with a LOD and LOQ. ${ }^{45,46}$

4.7.3. Repeatability, Reproducibility, and Intermediate Precision. The required precision was demonstrated by repeatability (at different sample concentrations), reproducibility (at different concentrations), and intermediate precision (under different laboratory conditions) to indicate the robustness and relative error of the developed method. These experiments were carried out for CSE samples as repeatability with three samples at two concentrations $(n=6 \times$ 3 ) and reproducibility of six concentrations $(n=6 \times 3)$, with intermediate precision $(n=6 \times 3)$. These parameters were investigated for preciseness, accuracy, and reproducibility of the HPLC method for the content of compounds (1-7).

4.7.4. Extraction Recovery and Solution Stability. The accuracy was determined by recovery values ranging from 80 to $110 \%$ spiked into different concentration levels of the target analytes with the solution stability for samples and standards until $42 \mathrm{~h}$.

4.8. Calculation of Apocarotenoids. The percentage of apocarotenoids $(1-7)$ was calculated from mean peak areas of the duplicate test solution injections and the mean triplicate mixed standard preparation injection producing the most similar peak areas using the formula

$\%$ content by HPLC-PDA

$$
\begin{aligned}
= & \frac{\text { mean peak area of sample }}{\text { mean peak area of standard }} \\
& \times \frac{\text { concentration of standard solution }(\mu \mathrm{g} / \mathrm{mL})}{\text { concentration of sample solution }(\mu \mathrm{g} / \mathrm{mL})} \\
& \times \text { purity of standard }(\%)
\end{aligned}
$$

4.9. Measurement of Uncertainty. The measurement and assessment uncertainty based on method validation and calibration conditions were estimated according to the procedures recommended by EURACHEM/CITAC Guide CG4/NABL 141 and protocol. ${ }^{47,48}$ The exercise includes (i) defining measurement criteria, (ii) identifying the sources of uncertainty, (iii) measuring the uncertainties, and (iv) calculating combined and expanded uncertainty. ${ }^{49}$

4.10. Assessment of Uncertainty. To accurately evaluate the true value of analysis, it is necessary to know the associated uncertainty in which a true value lies. The uncertainty sources were identified and represented in the Ishikawa diagram to identify the influential factors that will affect the analytical results, representing the cause-and-effect analysis. ${ }^{47,50} \mathrm{Un}$ certainty analysis applies to the whole analytical measurement process. We found that elemental uncertainties were assigned as either type $\mathrm{A}$ or type $\mathrm{B}$ during the uncertainty analysis. The difference is defined by the EURACHEM/CITAC Guide CG4/NABL 141 guideline. ${ }^{47,48}$ Type A uncertainty (systematic approach) is evaluated by the statistical analysis of method reproducibility $\left(U_{\text {rep }}\right)$ with analytical observations. Type A uncertainty cannot be used as the only estimate of the measurement uncertainty. Additional components such as uncertainty associated with laboratory operation (e.g., weighing, dilutions, and certified reference material), bias, instrumental operation (HPLC), and different analysts are considered.

Type A uncertainty was determined by measuring 10 batches of samples under conditions of reproducibility and repeatability. It was quantified using eq 2 as

$$
U_{\text {rep }}=\frac{\mathrm{SD}}{\sqrt{ } n}
$$

where $U_{\text {rep }}$ is the standard uncertainty of reproducibility, SD is the standard deviation, and $n$ is the independent observations.

For type B uncertainty instrument operation $\left(U_{\text {ins }}\right)$, laboratory operation including the weight of the standard, sample, its dilutions $\left(U_{\text {mass }}\right.$ and $\left.U_{\text {vol }}\right)$, and purity of reference standards $\left(U_{\text {ref }}\right)$ was identified as the random source of uncertainty. The uncertainty of instrument operation $\left(U_{\text {ins }}\right)$ was determined by measuring system suitability samples based on eq 2 .

The uncertainty of laboratory operation, including the weight of the standard and sample $\left(U_{\text {mass }}\right.$ and $\left.U_{\text {vol }}\right)$ considered as rectangular distribution, was estimated by dividing the expanded combined uncertainty $\left(U_{\text {cert }}\right.$ ) (a measured uncertainty from the certificate of analysis or other specification given by the manufacturer) by the coverage factor $K=2$ in eq 3.

$$
U_{\text {mass }} \text { or } U_{\text {vol }}=\frac{U_{\text {cert }}}{2}
$$

where $U_{\text {mass }}$ and $U_{\text {vol }}$ are the standard uncertainty of weighing and dilution, respectively, $U_{\text {comb }}$ is the combined uncertainty, and 2 is the coverage factor $(K)$. The uncertainty purity of reference standards $\left(U_{\text {ref }}\right)$ (in the case of the absence of the certificate) was estimated based on eq 4 derived from rectangular distribution.

$$
U_{\mathrm{ref}}=\frac{(100-P) / 100}{\sqrt{ } 3}
$$

where $U_{\text {ref }}$ is the standard uncertainty of the reference standard and $P$ is the purity given in manufacturer certificates. 
All the identified components, including type A and B, were combined by the rule of error propagation to evaluate the relative combined measurement uncertainty $\left(U_{\text {comb }}\right)$ using eq 5

$$
\begin{aligned}
& U_{\text {comb }}=\sqrt{{U_{\text {rep }}}^{2}+U_{\text {ins }}{ }^{2}+U_{\text {mass }}{ }^{2}+U_{\text {vol }}{ }^{2}+{U_{\text {ref }}}^{2}} \\
& U_{\text {exp }}=K \cdot \sqrt{{U_{\text {rep }}}^{2}+{U_{\text {ins }}}^{2}+{U_{\text {mass }}}^{2}+{U_{\text {vol }}}^{2}+{U_{\text {ref }}}^{2}}
\end{aligned}
$$

Finally, expanded combined uncertainty $\left(U_{\text {exp }}\right)$ was evaluated by multiplying the $U_{\text {comb }}$ with the coverage factor $(K)$ of 2 (95\% confidence level used), eq 6. This exercise helped find the precision and accuracy of these unstable apocarotenoids and their analysis for lab-to-lab variation. ${ }^{51}$

\section{ASSOCIATED CONTENT}

\section{SI Supporting Information}

The Supporting Information is available free of charge at https://pubs.acs.org/doi/10.1021/acsomega.1c03470.

Optimization of matrix extraction; HPLC-PDA validation optimization, linearity repeatability, and reproducibility precision studies; solution stability; LC-based ESIMS/MS identification and mass scan of apocarotenoids confirmed in CSE; Ishikawa diagram for factors affecting uncertainty in HPLC analysis of apocarotenoids in CSE based on a single-laboratory validation study; and HPLC-ESI-MS/MS chromatogram spectra in the positive and negative mode of KCS compounds from apocarotenoids and flavonoids classes in CSE (PDF)

\section{AUTHOR INFORMATION}

\section{Corresponding Author}

Aboli Girme - Analytical Development and Innovation Center and Pharmacognosy and Botany Center, Pharmanza Herbal Pvt. Ltd., Anand 388435 Gujarat, India; 이이.org/00000002-1536-1656; Email: ardm@pharmanzaherbals.com

\section{Authors}

Ganesh Saste - Analytical Development and Innovation Center, Pharmanza Herbal Pvt. Ltd., Anand 388435 Gujarat, India

Sandeep Pawar - Analytical Development and Innovation Center, Pharmanza Herbal Pvt. Ltd., Anand 388435 Gujarat, India

Chetana Ghule - Analytical Development and Innovation Center, Pharmanza Herbal Pvt. Ltd., Anand 388435 Gujarat, India; (1) orcid.org/0000-0001-6746-5361

Amit Mirgal - Pharmacognosy and Botany Center, Pharmanza Herbal Pvt. Ltd., Anand 388435 Gujarat, India; (i) orcid.org/0000-0002-1800-8364

Saurabh Patel - Analytical Development and Innovation Center, Pharmanza Herbal Pvt. Ltd., Anand 388435 Gujarat, India; (1) orcid.org/0000-0001-9275-1052

Anshuly Tiwari - Analytical Development and Innovation Center, Pharmanza Herbal Pvt. Ltd., Anand 388435 Gujarat, India; (1) orcid.org/0000-0001-6888-121X

Sautik Ghoshal - Pharmacognosy and Botany Center, Pharmanza Herbal Pvt. Ltd., Anand 388435 Gujarat, India; (1) orcid.org/0000-0001-5722-7810

Sandip B. Bharate - CSIR-Indian Institute of Integrative Medicine, Jammu 180001, India; 이이.org/0000-00016081-5787
Sonali S. Bharate - CSIR-Indian Institute of Integrative Medicine, Jammu 180001, India; Present Address: Shobhaben Pratapbhai Patel School of Pharmacy \& Technology Management, SVKM's NMIMS, V.L. Mehta Road, Vile Parle (W), Mumbai-400056, India; (1) orcid.org/0000-0001-7267-5080

D. Srinivasa Reddy - CSIR-Indian Institute of Integrative Medicine, Jammu 180001, India; 이이.org/0000-00033270-315X

Ram A. Vishwakarma - CSIR-Indian Institute of Integrative Medicine, Jammu 180001, India; Present Address: Council of Scientific \& Industrial Research, CSIR Headquarters, Anusandhan Bhavan, RafiMarg, New Delhi-110001, India.

Lal Hingorani - Analytical Development and Innovation Center and Pharmacognosy and Botany Center, Pharmanza Herbal Pvt. Ltd., Anand 388435 Gujarat, India

Complete contact information is available at:

https://pubs.acs.org/10.1021/acsomega.1c03470

\section{Notes}

The authors declare no competing financial interest.

\section{ACKNOWLEDGMENTS}

The authors would like to acknowledge CSIR-IIIM (Jammu, India) for the technology's initial development and its transfer to Pharmanza Herbal Pvt. Ltd. The authors also would like to acknowledge Ruchi Singh and Arun Kumar B. (Pharmanza Herbal Pvt. Ltd., Anand, India) for their assistance in the compounds identification.

\section{ABBREVIATIONS}

TIC, total ion chromatograms; KCS, Kashmir saffron (Crocus sativus L); CSE, Crocus sativus standardized extract; LOQ, limit of quantitation; LOD, limit of detection; PDA, photodiode array; DMSO, dimethyl sulfoxide; GI, geographical indications; HPLC, high-performance liquid chromatography; g, $\beta$-Dglucose sugar; $\mathrm{G}, \beta$-D-gentiobiose; $\mathrm{n}, \beta$-D-neopolitanose.s; $\mathrm{t}$, tri- $\beta$-D-glucose; MRM, multiple reaction monitoring; Rt, retention time; ESI-MS, electron spin ionization mass spectrometry; $\mathrm{u} / \mathrm{sec}$, unit/second

\section{REFERENCES}

(1) Husaini, A. M.; Kamili, A. N.; Wani, M. H.; Teixeira da Silva, J. A.; Bhat, G. N. Sustainable saffron (Crocus sativus Kashmirianus) production: technological and policy interventions for Kashmir. Funct. Plant Biol. 2010, 4, 116-127.

(2) Food and Agriculture Organization of the United Nations. Globally Important Agricultural Heritage Systems. URL (http:// www.fao.org/giahs/giahsaroundtheworld/designated-sites/asia-andthe-pacific/saffron-heritage-of-kashmir/en/) (accessed on 24 May, 2021).

(3) GI Registry. Geographical Indications Kashmir Saffron. URL (http://ipindiaservices.gov.in/GIRPublic/Application/Details/635) (accessed on 17 October, 2020).

(4) PTI. Saffron Bowl may now extend to northeast. URL (https:// www.theweek.in/wire-updates/national/2020/11/09/des21-dstsaffron.html) (accessed on 24 May, 2021).

(5) Union Territory of Jammu and Kashmir. Department of Agriculture and Farmers of Welfare Kashmir. URL (http:// diragrikmr.nic.in/assets/files/Saffron\%20Mission.pdf) (accessed on 24 May, 2021).

(6) Kandavel, S. Kashmir saffron gets GI tag. URL (https://www. thehindu.com/news/national/other-states/kashmir-saffron-gets-gitag/article31484569.ece) (accessed on 24 May, 2021). 
(7) Golden Saffron. Persian saffron vs Kashmiri Saffron vs other types. URL (https://www.goldensaffron.com/blog/health/persiansaffron-vs-kashmiri-saffron-vs-other-types) (accessed on 24 May, 2021).

(8) Cadwallader, K. R. Flavor chemistry of saffron. ACS Symp. Ser. 2001, 802, 220-239.

(9) Khanna, V. Cuisine and Diplomacy. URL (https://www.mea. gov.in/in-focus-article.htm?23938/Cuisine+and+Diplomacy) (accessed on 08 June, 2021).

(10) IKS Brand India Kashmir Saffron (Kashmir Kesar). How to make saffron milk during pregnancy for pregnant women / ladies. URL (https://www.indiakashmirsaffron.com/saffron-for-biryani-ikskashmir-saffron-for-hyderabadi-biryani-buy-saffron-for-biryani-onlinehow-to-make-saffron-color-for-biryani-best-quality-pure-originalauthentic-Kashmir-kesar/) (accessed on 08 June, 2021).

(11) Sengupta, S. Benefits of Kesar Doodh (Saffron Milk): 6 Incredible Reasons to Load Up On This Wonder Potion. URL (https://food.ndtv.com/food-drinks/6-incredible-benefits-of-kesardoodh-or-saffron-milk-you-must-know-1820377) (accessed on 08 June, 2021).

(12) Rana, S. Premenstrual Syndrome: Use Saffron To Prevent Menstrual Cramps During Periods. URL (https://food.ndtv.com/ health/premenstrual-syndrome-use-saffron-to-prevent-menstrualcramps-during-periods-1950482) (accessed on 08 June, 2021).

(13) Küpeli Akkol, E.; Tatlı Çankaya, I.; Şeker Karatoprak, G.; Carpar, E.; Sobarzo-Sánchez, E.; Capasso, R. Natural Compounds as Medical Strategies in the Prevention and Treatment of Psychiatric Disorders Seen in Neurological Diseases. Front Pharmacol. 2021, 12, 669638.

(14) Madhulika, N. Rice Kesar Kheer Recipe. URL (http:// indiangoodfood.com/2809-rice-kesar-kheer-recipe.html) (accessed on 08 June, 2021).

(15) Prakash, P. 6 Incredible Kahwa Tea Benefits, the Flavourful Kashmiri Green Tea. URL (https://food.ndtv.com/food-drinks/6incredible-kahwa-tea-benefits-the-flavourful-kashmiri-green-tea1680622) (accessed on 08 June, 2021).

(16) Goni, O.; Khan, M. F.; et al. Pharmacological insights on the antidepressant, anxiolytic, and aphrodisiac potentials of Aglaonema hookerianum Schott. J Ethnopharmacol. 2021, 268, 113664.

(17) Vieira, G.; et al. Antidepressant-Like Effect of Terpineol in an Inflammatory Model of Depression: Involvement of the Cannabinoid System and D2 Dopamine Receptor. Biomolecules 2020, 10, 792.

(18) Mzabri, I.; Addi, M.; Berrichi, A. Traditional and Modern Uses of Saffron (Crocus Sativus). Cosmetics 2019, 6, 63.

(19) Agha-Hosseini, M.; Kashani, L.; Aleyaseen, A.; Ghoreishi, A.; Rahmanpour, H. A.; Zarrinara, A. R.; Akhondzadeh, S. Crocus sativus L. (saffron) in the treatment of premenstrual syndrome: a doubleblind, randomised and placebo-controlled trial. BJOG: Int. J. ObstetGy. 2008, 115, 515-519.

(20) Batarseh, Y. S.; Bharate, S. S.; Kumar, V.; Kumar, A.; Vishwakarma, R. A.; Bharate, S. B.; Kaddoumi, A. Crocus sativus Extract Tightens the Blood-Brain Barrier, Reduces Amyloid $\beta$ Load and Related Toxicity in 5XFAD Mice. ACS Chem. Neurosci. 2017, 8, $1756-1766$.

(21) Talebi, M.; Talebi, M.; Samarghandian, S. Association of Crocus sativus with Cognitive Dysfunctions and Alzheimer's Disease: A Systematic Review. Biointerface Res. Appl. Chem. 2021, 11, 74687492.

(22) José Bagur, M.; Alonso Salinas, G.; Jiménez-Monreal, A.; et al. Saffron: An Old Medicinal Plant and a Potential Novel Functional Food. Molecules 2017, 23, 30.

(23) Zandi, N.; Pazoki, B.; Momeni Roudsari, N.; Lashgari, N.-A.; Jamshidi, V.; Momtaz, S.; Abdolghaffari, A. H.; Akhondzadeh, S. Prospects of Saffron and its Derivatives in Alzheimer's Disease. Arch. Iran. Med. 2021, 24, 233-252.

(24) Krishnaswamy, V. K. D.; Alugoju, P.; Periyasamy, L. Effect of short-term oral supplementation of crocin on age-related oxidative stress, cholinergic, and mitochondrial dysfunction in rat cerebral cortex. Life Sci. 2020, 263, 118545.
(25) Ochiai, T.; Shimeno, H.; Mishima, K.-i.; Iwasaki, K.; Fujiwara, M.; Tanaka, H.; Shoyama, Y.; Toda, A.; Eyanagi, R.; Soeda, S. Protective effects of carotenoids from saffron on neuronal injury in vitro and in vivo. Biochim. Biophys. Acta. 2007, 1770, 578-584.

(26) Wani, A.; Al Rihani, S. B.; Sharma, A.; Weadick, B.; Govindarajan, R.; Khan, S. U.; Sharma, P. R.; Dogra, A.; Nandi, U.; Reddy, C. N; Bharate, S. S; Singh, G.; Bharate, S. B.; Vishwakarma, R. A.; Kaddoumi, A.; Kumar, A. Crocetin promotes clearance of amyloid- $\beta$ by inducing autophagy via the STK11/LKB1-mediated AMPK pathway. Autophagy 2021, 1-20.

(27) Bharate, S. S.; et al. Pre-clinical development of Crocus sativus -based botanical lead IIIM-141 for Alzheimer's disease: Chemical standardization, efficacy, formulation development, pharmacokinetics, and safety pharmacology. ACS Omega 2018, 3, 9572-9585.

(28) Gupta, M.; Wani, A.; Ahsan, A. U.; Ali, M.; Chibber, P.; Singh, S.; Digra, S. K.; Datt, M.; Bharate, S. B.; Vishwakarma, R. A.; Singh, G.; Kumar, A. Safranal inhibits NLRP3 inflammasome activation by preventing ASC oligomerization. Toxicol. Appl. Pharmacol. 2021, 423, 115582 .

(29) Girme, A.; Pawar, S.; Ghule, C.; Shengule, S.; Saste, G.; Balasubramaniam, A. K.; Deshmukh, A.; Hingorani, L. Bioanalytical Method Development and Validation Study of Neuroprotective Extract of Kashmiri Saffron Using Ultra-Fast Liquid ChromatographyTandem Mass Spectrometry (UFLC-MS/MS): In Vivo Pharmacokinetics of Apocarotenoids and Carotenoids. Molecules 2021, 26, 1815.

(30) Tarantilis, P. A.; Tsoupras, G.; Polissiou, M. Determination of saffron (Crocus sativus L.) components in crude plant extract using high-performance liquid chromatography-UV-visible photodiodearray detection-mass spectrometry. J. Chromatogr. A. 1995, 699, $107-118$.

(31) Valle García-Rodríguez, M.; Serrano-Díaz, J.; Tarantilis, P. A.; López-Córcoles, H.; Carmona, M.; Alonso, G. L. Determination of Saffron Quality by High-Performance Liquid Chromatography. J Agric Food Chem. 2014, 62, 8068-8074.

(32) Moras, B.; Loffredo, L.; Rey, S. Quality assessment of saffron (Crocus sativus L.) extracts via HPLC-DAD-MS analysis and detection of adulteration using gardenia fruit extract (Gardenia jasminoides Ellis). Food Chem. 2018, 257, 325-332.

(33) Jug, U.; Glavnik, V.; Kranjc, E.; Vovk, I. HPTLCdensitometric and HPTLC-MS methods for analysis of flavonoids. J. Liq. Chromatogr. Relat. Technol. 2018, 41, 329-341.

(34) Carmona, M.; Zalacain, A.; Sánchez, A. M.; Novella, J. L.; Alonso, G. L. Crocetin esters, picrocrocin and its related compounds present in Crocus sativus stigmas and Gardenia jasminoides fruits. Tentative identification of seven new compounds by LC-ESI-MS. J. Agric. Food Chem. 2006, 54, 973-979.

(35) Sabatino, L.; Scordino, M.; Gargano, M.; Belligno, A.; Traulo, P.; Gagliano, G. HPLC/PDA/ESI-MS Evaluation of Saffron (Crocus sativus L.) Adulteration. Nat. Prod. Commun. 2011, 6, 1934578X110060.

(36) Tarantilis, P. A.; Tsoupras, G.; Polissiou, M. Determination of saffron (Crocus sativus L.) components in crude plant extract using high-performance liquid chromatography-UV-visible photodiodearray detection-mass spectrometry. J. Chromatogr. A. 1995, 699, $107-118$.

(37) Guijarro-Díez, M.; Nozal, L.; Marina, M. L.; Crego, A. L. Metabolomic fingerprinting of saffron by LC/MS: novel authenticity markers. Anal. Bioanal. Chem. 2015, 407, 7197-7213.

(38) Xu, S.; Ge, X.; Li, S.; Guo, X.; Dai, D.; Yang, T. Discrimination of Different Parts of Saffron by Metabolomic-Based Ultra-Performance Liquid Chromatography Coupled with High-Definition Mass Spectrometry. Chem. Biodivers. 2019, 16, No. e1900363.

(39) Han, J.; Wanrooij, J.; van Bommel, M.; Quye, A. Characterisation of chemical components for identifying historical Chinese textile dyes by ultra high-performance liquid chromatography photodiode array - electrospray ionisation mass spectrometer. $J$. Chromatogr. A. 2017, 1479, 87-96.

(40) Aiello, D.; Siciliano, C.; Mazzotti, F.; Di Donna, L.; Athanassopoulos, C. M.; Napoli, A. Molecular species fingerprinting 
and quantitative analysis of saffron (Crocus sativus L.) for quality control by MALDI mass spectrometry. RSC Adv. 2018, 8, 3610436113.

(41) Lech, K.; Witowska-Jarosz, J.; Jarosz, M. Saffron yellow: characterization of carotenoids by high performance liquid chromatography with electrospray mass spectrometric detection. J. Mass spectrum. 2009, 44, 1661-1667.

(42) Ni, Y.; Li, L.; Zhang, W.; Lu, D.; Zang, C.; Zhang, D.; Yu, Y.; Yao, X. Discovery and LC-MS characterization of new crocins in Gardeniae Fructus and their neuroprotective potential. J. Agric. Food Chem. 2017, 65, 2936-2946.

(43) Girme, A.; Saste, G.; Pawar, S.; Balasubramaniam, A. K.; Musande, K.; Darji, B.; Satti, N. K.; Verma, M. K.; Anand, R.; Singh, R.; Vishwakarma, R. A.; Hingorani, L. Investigating 11 Withanosides and Withanolides by HPLC-PDA and Mass Fragmentation Studies from Ashwagandha (Withania somnifera). ACS Omega 2020, 5, 27933-27943.

(44) U.S. Pharmacopoeia. US Pharmacopoeia and National Formulary [USP43-NF38]; United States Pharmacopeial Convention, Inc.: Rockville, Md, 2020; Vol. 43(5). USP General Chapter $<621>$ Chromatography 6853.

(45) International Conference on Harmonisation of Technical Requirements for Registration of Pharmaceuticals for Human Use. Validation of analytical procedures: text and methodology Q2(R1); ICH Harmonised Tripartite Guideline, 2005.

(46) Girme, A.; Saste, G.; Balasubramaniam, A. K.; Pawar, S.; Ghule, C.; Hingorani, L. Assessment of Curcuma longa extract for adulteration with synthetic curcumin by analytical investigations. J. Pharm. Biomed. 2020, 191, 113603.

(47) EURACHEM/CITAC Guide, Quantifying Uncertainty in Analytical Measurement; Ellison, S. L. R., Rösslein, M., Williams, A., Eds., 3rd ed.; Eurachem, 2012. Free download from: http://www. mea-surementuncertainty.org/mu/guide.

(48) Guidelines for Estimation and Expression of Uncertainty in Measurement (NABL 141)' by National Accreditation Board for Testing and Calibration Laboratories (NABL). Issue No.: 03 Issue date: 18-Jul2016, 2016; pp 1-48.

(49) Jebali, S.; Bahri, S.; Latrous, L. Estimation of measurement uncertainty and validation of HPLC for simultaneous determination of five antihistamines in pharmaceutical formulations. Accred Qual. Assur. 2020, 25, 147-159.

(50) Meyer, V. R. Measurement Uncertainty of Liquid Chromatographic Analyses Visualized by Ishikawa Diagrams. J. Chromatogr. Sci. 2003, 41, 439-443.

(51) Dias, M. G.; Camões, M. F.; Oliveira, L. Uncertainty estimation and in-house method validation of HPLC analysis of carotenoids for food composition data production. Food chem. 2008, 109, 815-824. 